\title{
A pesquisa em Direito: \\ Um testemunho sobre a pesquisa em grupo, o método "Sprechstunde" e a iniciação científica na pós-modernidade ${ }^{1}$
}

\author{
Cláudia Lima Marques
}

Doutora em Direito (Heidelberg), Mestre em Direito (Tübingen), Especialista em Integração Européia (Saarbrücken), Alemanha, Prof. Adjunto da Faculdade de Direito da Universidade Federal do Rio Grande do Sul, Depto. de Direito Público e Filosofia do Direito.

“...any viable education theory has to begin with a language that links schooling to democratic public life, that defines teachers as engaged intellectuals and border crossers, and develops forms of pedagogy that incorporate difference, plurality, and the language of the everyday as central to the production and legitimation of learning....Postmodern educational criticism offers the opportunity for a discursive practice, works in the interest of mankind... acknowledging difference as the basis for a public philosophy that rejects totalizing theories that view the Other as a deficit, and providing the basis for raising questions the dominant culture finds too dangerous to raise."(ARANOWITZ/GIROUX,Postmodern Education-Politics, Culture \& Social Criticism, University of MinnesotaPress, Mineapolis, 1993, p. 187e 188).

\section{Introdução}

12 inquietude, a curiosidade, o interesse pelo novo são características normais de quem está a aprender, de quem está desenvolvendo e acumulando conhecimentos, como os alunos de Direito de qualquer Universidade brasileira. Penso ser possivel direcionar e utilizar esta força de inquietude e de dúvida para a pesquisa científica, para a beleza da descoberta e da explicação da realidade, para o prazer de construir o pensamento, de desenvolver o raciocínio crítico, dedutivo ou indutivo, o prazer de desco-

brir a solução de um caso ou um problema da vida, para reconstruir o respeito e a admiração pelas descobertas e caminhos dos juristas que nos antecederam, para conhecer e acompanhar as novas descobertas e os novos caminhos dos juristas de hoje, para desenvolver uma visão própria da realidade, para admirar e descortinar a lógica - racional ou sentimental- das atuais soluções jurídicas para os velhos e novos conflitos e problemas de nossa sociedade.

${ }^{1}$ Trabalho apresentado no IX Encontro Nacional do CONPEDI -Conselho Nacional de Pesquisa e Pós-Graduação em Direito, PUC-RIO, no dia 19 de setembro (GTR4-Cooperação Interinstitucional e Programa Simon Bolívar) e discutido no dia 20 de setembro (GTEl-Direito Internacional e Integração regional: os efeitos da globalização). A autora gostaria de agradecer (e homenagear) ao Prof. Michael R. Will e ao Programa DAAD/CAPES pelo apoio recebido durante meu aprendizado na Alemanha. 
Pesquisar é pensar, refletir, ler, discutir, perguntar, criticar, descobrir, enfim, é buscar uma visão, uma explicação, uma idéia, uma solução para as perguntas e problemas que nos movimentam e interessam; é construir, formar e organizar um pensamento (próprio ou não); é alcançar um resultado que apazigúe ou que confirme a inquietude inicial.

Se pesquisar em Direito é algo tão simples e hermenêutico, quase natural e intrínseco a nossa ciência, porque é tratado como algo tão complexo, egoístico e exclusivo de poucos? As explicações são muitas, de jogos de poder, ${ }^{2}$ à influência do positivismo e do empirismo em nosso pensamento científico. ${ }^{3}$ Parece-me útil, pois neste IX Encontro Nacional do CONPED -Conselho Nacional de Pesquisa em Direito, refletir sobre esta pergunta e, analisar as respos-

tas atuais com uma visão pós-moderna. ${ }^{4}$ Quem sabe, assim poderei contribuir um pouco para uma - a meu ver, ainda necessária - reconstrução e redirecionamento de nossos próprios preconceitos em relação à pesquisa em Direito e pesquisa realizada em nossas Faculdades de Direito.

Neste sentido, gostaria de dividir minhas reflexões em duas partes. A primeira analisando a pesquisa em Direito na Universidade e as dificuldades de pesquisar hoje em Direito, conscientes da crise da pós-modernidade. ${ }^{5}$ A realidade é que, na Universidade e nas outras ciências, considera-se pouco a pesquisa realizada em Direito. Mister, pois, refletir o porquê deste preconceito contra a pesquisa jurídica, miste defender a pluralidade de métodos em pesquisa, ${ }^{6}$ especialmente em tempos pós-mo-

${ }^{2}$ Assim TRINDADE, Hélgio, Universidade, Ciência e Poder, in Universidade em ruinas, 2ed., Ed. Vozes, 2000 p. 14 a 21 .

${ }^{3}$ Assim ensina SAMAJA, Juan, Aportes de la metodologia a la refexión epistemológica, in in La posciencia-El conocimento científico en las postrimerías de la modernidad, Esther Díaz (Editora), Ed. Biblos, Buenos Aires, 2000 , p. 151

${ }^{2}$ Esta análise pós-moderna é uma homenagem ao mestre orientador de Doutorado, Prof. Dr. Dr.h.c. Erik Jayme, da Universidade de Heidelberg, que em seu brilhante curso de Haia lançou sua teoria dos reflexos da pós-modernidade no direito. Veja JAYME, Erik, Identité culturelle et intégration: Le droit internationale privé postmoderne in: Recueil des Cours de l' Académie de Droit International de la Haye, 1995, II, pg. 36 e seg.

${ }^{5}$ Sobre os reflexos da atual pós-modernidade, na pesquisa e na ciência do Direito, veja meu artigo A crise científica do Direito na pós-modernidade e seus reflexos na pesquisa, in Cidadania e Justiça-Revista da AMB, ano 3, n. 6 (1999), p. 237 e seg (republicado na Revista Arquivos do Ministério da Justiça) e no livro de Anais da Conferência , Rumos da Pesquisa-Múltiplas Trajetórias, Organizadoras Maria da Graca KRIEGER e Marininha Aranha ROCHA, Porto Alegre: Pró-Reitoria de Pesquisa/Ed.UFRGS, 1998, p. 95 a 108.

${ }^{6}$ Inspiro-me neste trabalho no livro de ARANOWITZe GIROUX (ARANOWITZ, Stanley e GIROUX, Henry A., Postmoder Education - Politics, Culture \& Social Criticism, University of Minnesota Press, Mineapolis, 1993) que demonstra como os paradigmas pós-modernos, como o pluralismo e o fim das metanarrativas absolutas e universais para todas as ciências (como por exemplo, o fim da tradicional metarrativa da necessidade do uso de métodos empíricos para uma pesquisa ser considerada "cientifica"), pode e deve ser usada para discutir a crise na educação e os nossos métodos universitários atuais: "Regardless of whether critics see postmodemism as pastiche, parody, or serious cultural criticism, the postmodern temperament arises from the exaustion of the still prevalling intellectual and artistic knowledge and the crisis of the institutions charged with their production and transmission - the schools. The "nihilism" of postmodem discourse does not signify ist rejection of ethir politisc, and power only its refissal to accept the givens of public and private morality and the judgements arising from the Of cour, a Of course, we gofurher in this book and arge that crilcal postmodemism provides a political and pedagogical basis no only for challenging current forms of academic hegemony but also for deconstructing conservative forms of postmodernism in which social life merely made over to accommodate expanding fields of information in which reality collapses into the proliferation of images. At its bests, a critical postmodernism signals the possibility for not only rethinking the issue of educational reform but also creating a pedagogical discourse that deepens the most radical impulses and social practices of democracy itself." (ARANOWITZ, Stanley e GIROUX, Henry A., Postmodern Education - Politics, Culture \& Socia Criticism, University of Minnesota Press, Mineapolis, 1993, p. 187).

Revista da Faculdade de Direito da UFRGS, v. 20, Outubro/2001 dernos, ${ }^{7}$ mister construir em atitude afirmativa ${ }^{8}$ recusando-se a sermos nós, juristas-pesquisadores, mais um instrumento de exclusão de preconceito em relação aos nossos colegas, das Universidades e das Instituições da sociedade, ${ }^{9}$ pesquisadores em Direito (Parte I). A segunda parte será dedicada aos problemas e dificuldades de se "ensinar a pesquisar em $\mathrm{Di}$ reito". Em nossa realidade acadêmica, a pesquisa extraclasse de estudantes, a pesquisa de iniciação científica, sem finalidade de nota ou para trabalhos de conclusão, é ainda muito pouco realizada no país. Como tive a sorte e o privilégio de ter sido pesquisadora-junior da Universidade de Saarlandes, do Instituto Max-Planck, na Alemanha e do Instituto Suíço de Direito Comparado, e, como desde minha entrada na Universidade Federal do Rio Grande do Sul, há 10 anos, tenho trabalhado em iniciação científica e pesquisa em grupo, penso poder contribuir à discussão com um testemunho. Quero

relatar aqui um pouco a forma, o método, as dificuldades e os resultados deste trabalho de pesquisa em grupo na Faculdade de Direito da UFRGS. Este testemunho tem como finalidade não só abrir a metodologia que desenvolvi para ensinar a pesquisar e que denominei "Sprechstunde", mas principalmente, como se trata de um caminho misto, altamente influenciado pelos métodos alemães e nãoconvencionais no Brasil, de ajudar a refletir sobre a necessária abertura de espírito em relação aos esforços dos colegas em iniciação científica e em ensino da pesquisa. Talvez, assim, possamos refletir um pouco sobre o normal "egoísmo" dos professorespesquisadores e do "fechamento" da redoma da pesquisa. ${ }^{10}$ Talvez, assim, possamos iniciar uma contratendência, de trabalho mais cooperativo, interdisciplinar, em grupo, respeitoso das diferenças e da pluralidade atual, em uma espécie de "criticismo educacional pós-moderno"11

${ }^{7}$ Defendo a idéia que a crise da pós-modernidade no Direito advém também da modificação dos bens economicamente relevantes, que na idade média eram os bens imóveis, na idade moderna, o bem móvel material e que na idade atual seria o bem móvel imaterial ou o desmaterializado "fazer" dos serviços, do soft ware, da comunicação, do lazer, da segurança, da educação, da saúde, do crédito. Se só este bens imateriais e fazeres que são a riqueza atual, os contratos que autorizam e regulam a transferência destas "riquezas" na sociedade também têm de mudar, evoluir do modelo de dar da compra e venda para modelos novos de serviços e dares complexos, adaptando-se a este desafio desmaterializante "pós-moderno". Veja nosso livro, Contratos, p.. 89 e seg. Os sociólogos preferem estudar o fenêmeno na mudança dos meios de produção: pré-industrial, industrial e pós-industrial ou inform o fentron inform o fentis Manuel, The rise of the network society, vol. I, The Inform Massachusetts, 1996/1999, p. 14 e seg.

${ }^{8}$ Segundo ROSENAU, Pauline Marie, Post-modernism and the social sciences, Princeton Univ. Press, Princenton, 1992, p. 117. Na classificação de ROSENAU, p. 53, seriam "skeptical" pós-modernos, para contraponto aos "affirmative" pós-modernos (ROSENAU p. 57), estes últimos clamam por reconstrução e utilização de parte das metanarrativas da modernidade, como a posição defendida neste artigo.

${ }^{9}$ Mister frisar que a pesquisa em Direito näao está restrita às Faculdades e Universidades, ao contrário, após minha experiência em Institutos de pesquisa na Alemanha e Suíça e no Brasilcon-Instituto Brasileiro de Política e Direito do Consumidor, considero que no futuro a pesquisa, também no Brasil, se fará tanto nas universidades como nas organizações e Instituições do Terceiro Setor.

${ }^{10}$ Defendi o pluralismo na pesquisa escrevi no trabalho "A crise", p. 95 e seg.

${ }^{11} \mathrm{~A}$ expressão "Postmodern educational criticism" é um tanto incongruente, pois a crítica é típica da modernidade, mas esta expressão foi usada por ARANOVITZ/GIROUX, p. 188, para descrever sua teoria de reconstrução da educação, de forma democrática, plural e crítica em plena pós-modernidade: "Postmodern educational criticism points to need for constructing a critical discourse to both constitute and reorder the ideological broader parameters of a radical democracy"

Revista da Faculdade de Direito da UFRGS, v. 20, Outubro/2001 
também em Direito. ${ }^{12}$

compreensão da realidade e fundamentação do conhecimento, um modo empírico: "El pensamento científico abandonó la incuestiona-

\section{A pesquisa em Direito na Universidade}

Como ensina Pádua, em "um sentido amplo, pesquisa é toda atividade voltada para a solução de problemas, como atividade de busca, indagação, investigação, inquirição da realidade, é a atividade que vai nos permitir, no âmbito da ciência, elaborar um conhecimento, ou um conjunto de conhecimentos, que nos auxilie na compreensão desta realidade e nos oriente em nossas ações."13

Durante os séculos XVI e XVII assentaram-se as bases epistemológicas e metodológicas do saber científico moderno, ${ }^{14}$ no qual Galileu Galilei, Isaac Newton e Johannes Kepler são considerados precursores, e que resultou na constituição de um modo novo de pensamento medieval para opornele la legitimidad y la fuerza de los hechos empíricos. La razón vinculada con la experiencia permitió el conocimiento de los fenómenos físicos natureales. La observación, la experimentación y la medición fueron las metodologías fundamentales que facilitaron esta fructifera relación entre teorías y hechos." 15

Os êxitos alcançado nas ciência exatas permitiram aos pensadores do século XVII transferir esta visão "científica" para as análises dos fenômenos sociais, forçando as ciências sociais e aplicadas, ${ }^{16}$ como o Direito, para ter "validade" e alcan çar a "verdade", a utilizar estes métodos. ${ }^{17}$ Estava aberta a crise do método de pesquisa em Direito.

${ }^{12}$ Para alguns, esta é uma tarefa muito difícil, que exige uma volta ao pensamento epitesmologico. Assim o mestre argentino Carlos Alberto Ghersi (GHERSI, Carlos Alberto, Tercera Via-Âmbito Jurídico, Ed. Gowa, 2000), considera que a pósmodernidade construiu um perigoso subjetivismo jurídico e uma metodologia abstrata de ensino, que abstrai da realidade e quivition como um fim em si mesmo (p. 44), a destruir a própria validade e função social do Direito (p. 45). Prega o autor uma contratendência (p. 33), que "el derecho debe enseñarse como fenómeno social complejo" e com recurso às outras ciências pois "definir la frontera de una ciencia, es limitar la investigación, es no permitir la consubstanciación o entrecruzamento de los saberes, lo social es un todo inescindible, pues apunta a la humanidad en comunidade, parcializada en Estados o globalizada en un solo mundo"(p. 33 e 34) e conclui: "Pensamos que a partir de involucrar el derecho con los saberes que están en lo social, mostramos aspectos de las normas que las sumergen en un mundo de contradicciones y de causalismos; la contextuación enfrenta así a la abstracción individualista, es la

${ }^{13}$ Assim define pesquisa, PÁDUA, Elisabeth Matallo Marchesini de, Metodologia da pesquisa- Abordagem teórico-prática, Ed. Papirus, 2.ed, Campinas, 1997, p. 29

${ }^{14}$ Assim ensina Trindade, op. cit., p. 14

${ }^{15}$ LUQUE, Susana de, El objeto de estudio en las ciencias sociales, in La posciencia-El conocimento científico en las postrimerías de la modernidad, Esther Díaz (Editora), Ed. Biblos, Buenos Aires, 2000, p. 223. corriente de reacción o su contratendencia."(p. 37).

${ }^{16}$ Sobre o tema das especificidades das áreas das ciências e a cada vez maior distinção entre "ciência básica" e "ciência aplicada", veja síntese do congresso,REGNER, Anna Carolina K. P. , O fazer cientifico: as especificidades das áreas e uma nova agenda para a ciência, in Rumos da Pesquisa-Múltiplas Trajetórias, Organizadoras Maria da Graça KRIEGER e Marininha Aranha ROCHA, Porto Alegre: Pró-Reitoria de Pesquisa/Ed.UFRGS, 1998, p. 273.

${ }^{17}$ Assim LUQUE, La posciencia, p. 223: "Los éxitos alcanzados en el ámbito de las ciencias físicas impulsionaron a los pensadores del siglo XVII a trasladar la mirada científica hacia dos fenómenos sociales... [las ciencias sociales] sólo alcanzarían la verdad en la emedidad en que siguieran el modelo de la físico-matemática..."

Revista da Faculdade de Direito da UFRGS, v. 20, Outubro/2001

A) Dificuldades da pesquisa em Direito e do diálogo Universitário em tempos pós-modernos

O termo "método", usado no contexto da pesquisa científica, tem um duplo significado: a) pode evocar os procedimentos para obter um conhecimento, para descobri-lo, para conhecê-lo, para investigá-lo e b) pode evocar os procedimentos para "validar" ou "justificar" um conhecimento, uma assertiva, um resultado que já se sabe. ${ }^{18}$

A dificuldade básica da pesquisa em Direito é seu método, apesar de ser polêmico também seu resultado. ${ }^{19}$ Efetivamente, em Direito, é polêmico tanto o método de pesquisa (método de investigación) ${ }^{20}$ em si, quanto o método de validação da pesquisa jurídica (método de justificación) ${ }^{21}$ A primeira crise foi de seu método de validação. Nos séculos XIX e $\mathrm{XX}$, o Wienerkreis, o Círculo de Viena com Carnap $^{22}$ e o fundador da sociologia empírica e do método positivista, Auguste Comte, ${ }^{23}$ acabaram por defender, contra toda metafísica e especulação, que somente o que se podia explicar positivamente e empiricamente teria valida-

de científica. Isto teve enorme repercussão na Filosofia, na Religião e no Direito. Inicialmenteo Direito não mudou seus métodos de pesquisa, de procura, de investigação e de "descoberta" dos conhecimentos, continuou utilizando o método hermenêutico (dogmático e dedutivo) ${ }^{24}$ típico desde os estudos dos livros romanos na Idade Média, o que resultou em uma grande crise de validação (ou de justificação) para a pesquisa em Direito, ajudando no triunfo do método positivista, único considerado "científico" à época. ${ }^{25}$

\section{O método hermenêutico e o menosprezo pela pesquisa em Direito: a falta de validação ou justificação dos métodos qualita- tivos}

Por muito tempo, os pensadores menosprezaram a importância e mesmo a possibilidade de se pesquisar em Direito. ${ }^{26}$ Sem querem repetir esta discussão estéril (e hoje felizmente

${ }^{18}$ Assim ensina SAMAJA, Juan, Aportes de la metodologia a la refexión epistemologica, in in La posciencia-El conocimento científico en las postrimerías de la modernidad, Esther Díaz (Editora), Ed. Biblos, Buenos Aires, 2000, p. 151.

${ }^{19}$ Os hoje denominados produtos da pesquisa em Direito são incialmente os mesmos das outras ciências: livros, artigos, estudos, relatórios, palestras, conferências etc. Mas também os resultam indiretamente da pesquisa em Direito o próprio "objeto" ou Direito, uma lei, um Tratado, uma doutrina nova, um parecer opinativo ou consultivo, um trabalho forense, uma decisão de líder. Estes são normalmente desconsiderados como produtos da ciência, pois fáticos-jurídicos.

${ }^{20}$ Segundo ensina GIANELLA, p. 78: "[Los métodos de investigación]... están dirigidos al incremento del conocimiento, a conocer neuvos hechos, propriedades, relaciones y regularidades.” (GIANELLA, Alicia E., Introduccion a la epistemologia y la metodologia de la ciencia, Ed. da la Universidad Nacional de la Plata, La Plata, 1995, p.78).

${ }^{21}$ Segundo ensina GIANELLA, op. cit., p. 78: "[Los métodos de validación o justificación] tiene por función ejercer una espécie de "control de calidad" de los conocimientos, evaluar las hipótesis y teorías desde los fundamentos que ofrecen."

${ }_{22}^{2}$ Assim ensina SAMAJA, op. cit., p. 152.

${ }^{23}$ Assim ensina SAMAJA, op. cit., p. 152.

${ }^{24}$ Assim as palavras clássicas de Reinhold Zippelius: "Der Gegenstand bestimmt die Methode", ZIPPELIUS, Reinhold, Juristische Methodenlehre, 5. Aufl., Beck, München, 1990, p. 1

${ }^{25}$ PÁDUA, op. cit., p. 31

${ }^{26}$ Veja sobre o tema as reflexões de ZITSCHER, Harriet Christiane, Como pesquisar?, in Revista da Faculdade de Direito da UFRGS, vol. 17(1999), p. 103 e seg., que distingue entre pesquisa conceitual/dogmática e pesquisa empírica, também no Direito. 
quase superada), ${ }^{27}$ gostaria apenas de destacar que esta visão é típica da mono-metodologia da idade moderna e não mais condiz com o pluralismo de métodos ${ }^{28}$ da idade atual ou pósmoderna. ${ }^{29}$

Como ensina Pádua: "Até meados do século $X X$, considerou-se como científico o conhecimento produzido a partir das bases estabelecidas pelo método positivista, apoiado na experimentação, mensuração e controle rigoroso dos dados (fatos), tanto nas ciências naturais como nas ciências humanas. Associou-se a idéia de cientificidade à pesquisa experimental e quantitativa, cuja objetividade seria garantida pelos instrumentos e técnicas de mensuração e pela neutralidade do próprio pesquisador frente à investigação da realidade. Com o desenvolvimento das investigações nas ciências humanas, as chamadas pesquisas qualitativas procuraram consolidar procedimentos que pudessem superar os limites das análises meramente quantitativas. A partir de pressupostos estabelecidos pelo método dialético, e também apoiadas em bases fenomenológicas, pode-se dizer que as pesquisas qualitativas têm se preocupado com o significado dos fenômenos e processos sociais, levando em consideração as motivações, crenças, valores, representações sociais, que permeiam a rede de relações sociais. Como estes aspectos não são passiveis de mesuração e controle, nos moldes da ciência dominante, sua cientificidade tem sido freqüentemente questionada." 30

Relembre-se, porém, que na Idade Média, o método científico era exclusivamente hermenêutico. Quando surgiram as primeiras Universidades, a hermenêutica é a ciência por excelência, ciência da compreensão e da interpretação dos textos, das escrituras e das leis. As três primeiras Faculdades organizadas foram justamente de Teologia (Filosofia), Direito e Medicina. ${ }^{31}$

O Direito, Teologia e Filosofia constroem seus conhecimentos, sua ciência, seu saber de forma hermenêutica. É historicamente, pois, recente considerar-se científico apenas o método empírico, da reação de Galilei até a formulação do empirismo por Locke e outros. Como vimos anteriormente, é somente nos séculos XIX e XX que chegarão os pensadores a considerar o método empírico, mais afeito às ciências exatas e ciências outras do que ao Direito, como o único científico, em uma visão perfeccionista típica das crenças universais e absolutas da idade moderna. ${ }^{32} \mathrm{O}$ método hermenêutico e tradicional do Direito causa espécie, é considerado problemático, não científico ou não-válido. É preciso fugir deste método, separar-se, é preciso medir, comparar, preparar estudos empíricos e quantitativos sobre a realidade, para que a pesquisa em Direito seja científica.

Passa-se a menosprezar a forma de produção do conhecimento jurídico até então existente, menosprezam-se os juristas e doutrinadores desta época, como não-científicos. Força-se o Direito a mudar, a usar métodos outros e com exclusividade, como se a comple-

${ }^{27}$ Assim, bastante pós-moderna, REGNER, op. cit., p. 274.

${ }^{28}$ Sobre pluralismo de métodos, como reflexo nessário dos tempos atuais, veja JAYME, Curso, p. 36 e seg.

${ }^{29}$ Veja uma bela defesa do pluralismo, in SILVA, Tomaz Tadeu, A produção social da identidade e da diferença, in Identidade e Diferença, Coord. SILVA, Tomaz Tadeu, Ed. Vozes, São Paulo, 2000, p. 73. Veja também excepcional sobre pluralismo no Direito, FRIEDMAN, Lawrence, The Republic of Choice, Cambridge, Harvard University Press, 1994, p. 11 e seg. Como explica Vattimo em sua introdução, " $O$ pós de pós-moderno indica, com efeito, uma despedida da modernidade...", veja VATTIMO, Gianni, o fim da modernidade- niilismo e hermenêutica na cultura pós-moderna, São Paulo, Martins Fontes, 1996, p. VII.

${ }^{30}$ PÁDUA, op.cit., p. 31.

${ }^{31}$ Veja sobre a universidade medieval, TRINDADE, op. cit., p. 12

${ }^{32}$ PÁDUA, op. cit., p. 31.

Revista da Faculdade de Direito da UFRGS, v. 20, Outubro/2001 xa realidade social pudesse ser compreendida e captada apenas pelos métodos empírico e de pesquisas quantitativas.

Em nossas Universidades ainda hoje encontramos alguns que pensam que o caráter científico (da pesquisa) depende do uso de métodos empíricos. Criticam os juristas e seus métodos, criticam sua falta de dedicação à pesquisa, à Universidade, sua baixa produção "científica", sua preocupação com a prática, sua falta de profissionalismo. ${ }^{33}$ Mal ou bem este menosprezo estrutural pelo método hermenêutico usado no Direito contribuiu para o isolamento (e fechamento) do pensamento, do discurso e das atividades científicas dos juristas nas Universidades. Se nos séculos XVIII e XIX, o Direito era ciência de destaque e os juristas consistiam na elite pensante daquelas sociedades, no século XX, a partir da década de 60, com a reforma das universidades e com um novo "cientifismo-neutro" imposto as Faculdades de Direito, esta posição científica de destaque, modificou-se, isolando ainda mais nossos predecessores. As Faculdades de Di- reito passaram a valorar e a elaborar seu pensamento científico de forma distinta das demais ciências sociais, ${ }^{34}$ em uma independência de "descompreensão" e falta de diálogo. A pesquisa era individual, por interesse próprio dos docentes ${ }^{35}$ ou comercial das editoras, ${ }^{36} \mathrm{sem}$ chegar aos alunos e muito menos aos colegas de outras áreas. ${ }^{37}$

A avaliação da produção científica oriunda das Faculdades, porém, veio da Universidade, utilizando seus métodos, seus critérios, seu empirismo, suas perguntas ao trabalho realizado pelos juristas, poucas vezes foi este classificado de científico. Chegamos ao ponto de documentos oriundos da universidade considerarem que não havia "pesquisa científica" nas Faculdades de Direito, apesar da representativa produção intelectual, especialmente livros de grande repercussão lá realizados. ${ }^{38}$ Importantes eram estátisticas de "impacto", a repercussão abstrata dos veículos utilizados para publicação nacional e internacional e não as citações ou a repercussão, prática que nossos mestres conseguiram nos Tribunais, na
${ }^{33}$ Efetivamente, TRINDADE, p. 12 comprova que o "profissionalismo" na universidade está intimamente ligado à pesquisa e à dedicação acadêmica, desde o século XVIII: "Com a criação das academias científicas, intensificase a profissionalização das ciências, fato que vai permitir sua inserção nas universidades através da pesquisa. Até o século XVII, o cientista não tem um papel especializado na sociedade, mas a partir dai desencadeia-se uma mudança profunda no sistema de valores e normas universitárias, reconhecendo-se, não sem conflitos, a mudança profunda no sistema de valores e normas universitarias, reconhecentade de uma atividade relacionada com as ciências em geral" (p. 12)
legitidade

${ }_{34}$ Assim OLIVEIRA, Luciano e ADEODATO, João Maurício, O Estado da Arte da pesquisa jurídica e sócio${ }^{34}$ Assim OLIVEIRA, Luciano e ADEODATO, João Maurício, O Estado da Arte da pesquisa juridica e sócio-
jurídica no Brasil, Ed. CJF/CEJ, Brasília, 1996, p. 11: "Há um notório descompasso entre a pesquisa jurídica e o estágio atual" nas outras ciências.

${ }^{35}$ Bastante críticos, OLIVEIRA/ADEODATO, p. 12, usam a expressão “ quase diletante” para descrever a pesquisa das Faculdades de Direito desta época.

${ }^{36}$ Não se pode desconhece o fato do mercado editorial de livros jurídicos estar muito ligado aos nomes da academia. Veja no Brasil, a tradição em publicações dos professores, por exemplo, da Faculdade Largo de São Francisco da USP.

Francisco da USP.
${ }^{37}$ OLIVEIRA/ADEODATO, p. 11, comprovam que a pesquisa jurídica está quase toda concentrada nas Univer${ }^{37}$ OLIVEIRA/ADEODATO, p. 11, comprovam que a pesquisa jurídica está quase toda concentrada nas Univer-
sidades Públicas, mas que o "debate sobre a pesquisa e o ensino jurídico no Brasil remonta a San Thiago Dantas e Ridades Públicas, mas

${ }^{38}$ Surpreende o número de publicações dos professores da Faculdade de Direito de 1904 a 1975, levantadas no livro de nosso falecido professor SANTOS, João Pedro, A Faculdade de Direito de Porto Alegre- Subsídios para sua História, Ed. Síntese, Porto Alegre, p. 189 a 277 e p. 341 a 370.

de Kuhn e a evolução da epistemologia, veja em português, BOMBASSARO, Luiz Carlos, Ciência e Mudança conceitual- Notas sobre Epitesmologia e História da Ciência, Edipucrs, Porto Alegre, 1995, p. 61 e seg. 
sociedade, nas leis que ajudaram a realizar, nas Constituições e na jurisprudência em geral. ${ }^{39}$ Chegamos a ponto de considerar não-cientistas, os grandes autores e doutrinadores do $\mathrm{Di}$ reito do início deste século. ${ }^{40}$

A incorreção desta lógica de exclusão da produção jurídica da Universidade repousa principalmente em sua visão metodológica reduzida. Um exemplo pode esclarecer: os médicos, geralmente, também dedicam pouco tempo à Universidade, praticam e realizam suas técnicas na sociedade, modificam a realidade e aplicam sua ciência em prol da coletividade. Nunca ninguém, porém, acusaria estes brilhantes professores e práticos da medicina de não-científicos. E porque não? Simplesmente por que Medicina, ao contrário do Direito e da Teologia, sempre utilizou o método empírico. Fáci acusar um hermenêuta de "a-científico", dificílimo acusar um médico, que usa quase que exclusivamente os métodos empíricos, de não científico. Observem, pois, como cala fundo este preconceito, pré-concebido mito de uma só metodologia científica para a pesquisa. Se a

dedicação de nossos predecessores foi pouca à Universidade e à pesquisa então considerada científica, também foi grande a falta de compreensão quanto as especificidades de nossa ciência e métodos tradicionais.

Bem, hoje, nós juristas, superamos os preconceitos, o sentimento de vergonha de nosso próprio método, repensamos nosso papel na Universidade, envidamos esforços pelo pluralismo de pensamento e multiplicação da pesquisa jurídica, aceitamos e utilizamos muitos métodos e discursamos sobre a pesquisa quase de iguais para iguais com as outras ciência sociais. ${ }^{41} \mathrm{O}$ pluralismo de métodos, de abordagens, de procedimentos na pesquisa jurídica é uma realidade. ${ }^{42}$ As pesquisas qualitativas de hoje não usam apenas o método hermenêutico, o comparatista e o histórico, mas há também a análise jurisprudencial qualitativa ou discursiva, o estudo das diferenças no Direito Comparado Pós-moderno, ${ }^{43}$ sem falar no crescente uso das pesquisas quantitativas no Direito, como o estudo de casos, ${ }^{44}$ como a aná-

${ }^{39}$ Como ensina LOPES, José Reinaldo de Lima, Direito e Transformação Social, Belo Horizonte, Ed. Nova Alvorada, 1997, p. 77, tanto o Direito faz parte da cultura, quanto possui sua própria cultura e reflexos típicos na sociedade: "...o sistema jurídico é constituído de uma "cultura". São as atitudes que fazem do sistema um todo. uma unidade, e que determinam o lugar dos aparelhos e das normas na sociedade globalmente considerada. A cultura jurídica engloba tanto as atitudes, hábitos e treinamento dos profissionais quanto do cidadão comum." Tal linha de pensamento possui tradição no Brasil, através da escola de Recife e a influência do „culturalismo jurídico" de Tobias Barreto, sobre o tema veja o nosso Artigo, Cem anos de BGB e o Código Civil Brasileiro, in: Revista dos Tribunaus vol. 741, p. $21 \mathrm{e} \mathrm{seg}$

${ }^{40}$ Sobre a intolerância científica como forma de manutenção de paradigmas, veja KUHN, Thomas, Die Struktur wissenschaftlicher Revolutionen, Suhrkamp, Frankfurt, 1996, p. 38 e seg, sobre o neo-radicalismo, como resposmodernismo, Raza o modermismo, Razao e Religião, Institu Plaget, Lisboa, 1922, p. 70 e seg. O autor denomina esta última vertente neo-ortodoxa de "uina de Kuhn e a evolução da epistemologia, veja em português, BOMBASSARO, Luiz Carlos, Ciência e Mudança conceitual- Notas sobre Epitesmologia e História da Ciência, Edipucrs, Porto Alegre, 1995, p. 61 e seg.

${ }^{41}$ Veja Zitscher, Como pesquisar?, p. 104 a 107.

${ }^{42}$ Veja bom exemplo deste pluralismo no recente livro de VENTURA, Deisi, Monografia Jurídica- uma visão prática, Ed. Livraria dos Advogados, Porto Alegre, 2000, p. 76 a 78.

${ }^{43}$ Veja sobre o tema JAYME, Erik, Visões para uma teoria pós-moderna do Direito Comparado, in Revista dos Tribunais nr. 759 , janeiro 1999 , p.24 a 40

${ }^{44}$ Veja sobre o tema ARAÚJO, Nádia, Formação do jurista pesquisador: Pressupostos e requisitos. Técnicas de pesquisa e ensino na pós-graduação, in Revista Direito, Estado e Sociedade, nr. 14, jan./julho. 1999, PUC/RJ, p. 23 a 37.

Revista da Faculdade de Direito da UFRGS, v. 20, Outubro/2001 lise jurisprudencial ${ }^{45}$ e a pesquisa de campo, em suas mais variadas formas. ${ }^{46}$ Geralmente, hoje optamos por uma combinação de método de investigação. Com a consolidação da pósgraduação no país, a produção científica no Direito aumentou fortemente, ${ }^{47}$ assim como o profissionalismo do professor-pesquisador. $\mathrm{O}$ que parecia um avanço calmo e certo, porém, sofre com a perda de modelo com a crise social da pósmodernidade. ${ }^{48}$ É necessário continuar a construir. ${ }^{49}$

\section{Crise da pós-modernidade: "desconstrução" do Direito e novo acirramento metodológico}

Efetivamente, veio a crise da pósmodernidade, ${ }^{50}$ as incertezas e o caos atingiram todas as ciências. ${ }^{51}$ Por ironia do destino, foi justamente a ciência do Direito uma das que mais se descontruiu com a crise da pós-

${ }^{45} \mathrm{Bom}$ exemplo é a pesquisa quantitativa e qualitativa de jurisprudência gaúcha sobre seguro-saúde e o CDC realizada pelo Grupo de Pesquisa CNPq "Mercosul e Direito do Consumidor", coord. Claudia Lima Marques e Harriet C. Zitscher, conjuntamente com estudantes, cujo Relatório foi publicado na Revista Direito do Consumidor (São Paulo), vol. 29, jan/mar 1999, p. 88 a 105.

${ }^{46}$ Bom exemplo de pesquisa de campo é fornecido por RIZZATTO NUNES, Luiz Antônio, Manual da Monografia Jurídica, 2. ed., Ed. Saraiva, São Paulo, 1999, p. 22.

${ }^{47}$ Veja sobre o tema, trazendo lista das monografias publicadas no país de 1980 a 1995, LEITE, Eduardo de Oliveira, A monografia jurídica, Ed. Revista dos Tribunais, 3. ed., 1997, p. 288 e seg.

${ }^{48}$ Assim MINDA, Garry, Postmodern Legal Movements- Law and Jurisprudence at Century's end, New York University Press, New York, 1995, p. 247 e, conclusão, p. 249: "Academic trends in legal scholarship do not occur in a vaccum, nor are law schools and legal scholars autonomous. To understand what has been going on in contemporary legal theory, one must look to what has been going on at the university... an intellectual and cultural revolution is now under way at American Universities... The crisis of representation, known as postmodernism, has reached the legal academy and it is represented by a new form of postmodern jurisprudence" Veja como ZIMA, Peter, Moderne/Postmoderne, UTB, Francke, Tübingen, 1997, p. 61, identifica nos movimentos neo-liberais conservadores e economicistas (de direita) um dos braços da pós-modernidade. Assim também MINDA p. 83, identifica o movimento conservador de "direita" da análise econômica do Direito como pósmoderno.

${ }^{49}$ Assim também, para todas as ciências sociais, conclui REGNER, p. 276

${ }^{50} \mathrm{Assim}$ manifestou-se ROSENAU, 1992, p. 124: "Legal theory is an arena where post-modern views of epistemology and method have created one of the most serious intellectual crises, questioning the very legitimacy of judicial systems and the integrity of legal studies."

${ }^{51}$ Como antes escrevi, A crise, p. 99: "A realidade denominada pós-moderna (LYOTARD, 1994, p. 13) é a realidade da pós-industrialização, do pós-fordismo, da tópica, do ceticismo quanto às ciências, quanto ao positivismo (HABERMAS, 1992, p. 35); época do caos, da multiciplicidade de culturas e formas, do Direito à diferença, da "euforia do individualismo e do mercado",(GHERSI, p. 27) da globalização e da volta ao tribal. É a realidade da substituič̃o do Estado pelas empresas particulares, de privatizações, do né-liberalismo, de terceirizações, de comuica do Ea , $1994, \mathrm{p} .13)$, de ceticismo sobre 0 geral, de um individualismo necessário, da coexistência de muitas meta-narrativas simultâneas e contraditórias, da perina dos vares modernos, esculpidos pela revolução burguesa e substituídos por uma ética meramente discursiva e argumentativa, de legitimação pela linguagem, pelo consenso momentâneo e não mais pela lógica, pela razão ou somente pelos valores que apresenta (KAUFMANN, 1994, p. 224 ). É uma época de vazio, de individualismo nas soluções (LIPOVETSKY, 1996, p. 7) e de insegurança jurídica, onde as antinomias são inevitáveis e a de-regulamentação do sistema convive com um pluralismo de fontes legislativas e uma forte internacionalidade (JAYME, 1995, p. 36) das relações. É a condição pós-moderna que, com a pós-industrialização e a globalização das economias, ja atinge América Latina e tem reflexos importantes na ciência do Direito. É a crise do Estado do Bem-Estar Social." a América Latina e tem reflexos importantes na ciência do Direito. É a crise do Estado do Bem-Estar Social."

Revista da Faculdade de Direito da UFRGS, v. 20, Outubro/2001 
modernidade, mas uma das últimas a se dar conta sobre os efeitos desta crise em sua ciência, talvez por seu isolamento ainda existente. Como ensina Rosenau, conhecer o fenômeno da pósmodernidade e seus efeitos nas ciências sociais é o melhor caminho para superar seu efeito destruidor: "Postmodernism haunts social science today. In a number of respects, some plausible and some preposterous, post-modern approaches dispute the underlying assumptions of mainstream social science and ist research product over the last three decades. The challenges post-modernism poses seem endless. It rejects epistemological assumptions, refites methodological conventions, resists knowledge claims, obscures all versions of truth, and dismisse policy recommendations. If social scientits are to meet this challenge and take advantage of what post-modernism has to offer without becoming casualities of it excesses, then an adequate understanding of the challenge is essential." 52

Sobre o tema já escrevi de forma crítica e ativista que: "Se o desafio do passado era ver a pesquisa em Direito reconhecida como tal na Universidade, o desafio do presente é superar a crise da pós-modernidade, de forma reconstruir uma razão para a pesquisa jurídica e viabilizar um avançar do Direito no futuro.A reação necessária é, pois, de uma pes

quisa renovada, ao mesmo tempo científica e jurídica, plural e tolerante, como se está tentando fazer na Faculdade de Direito da UFRGS,$^{53}$ apesar das dificuldades. Pesquisa renovada esta que, consciente da crise pósmoderna, possa responder à crescente disputa vazia de formas, métodos e linhas de pensamento, que ameaçam hoje devastar as nossas Faculdades, reduzindo-as em um misto de radicalismo, intolerância e passividade científica no final de século. Pesquisa esta que demonstre que a ciência do Direito ainda possui um valor em si mesmo, que o Direito ainda pode e deve dar respostas aos problemas do homem em sociedade e não só pesquisar sobre seu método, sua ideologia, seu discurso, seus atores, suas relações de poder, isto é, que a ciência do Direito ainda está legitimada a procurar o justo e o eqüitativo, apesar da sua atual e profunda crise de fundamentos.

... Neste sentido, como Rosenau, mister alertar que ao quebrar sua legitimidade como ciência de conduta, a crise pós-modernidade levou a uma desconstrução dos fundamentos do Direito tão profunda que nenhuma teoria ou linha de pensamento mais seria absolutamente válida e a pesquisa teria ficado "sem objeto". ${ }^{54}$ O foco o ponto de concentração seria qualquer outro objeto que não o Direito,

\section{${ }^{52}$ ROSENAU, p. 3.}

${ }^{53}$ Destaque-se que no livro da Pesquisa UFRGS de 1988 a 1992, a Faculdade de Direito aparece com 41 professores, autores de livros e artigos, no Brasil e exterior, denotando que mais da metade dos professores 80 professores da instituição e $70 \%$ dos professores ativos de sala de aula fazem pesquisa e submetem-se à crítica através de publicacões. No livro da Pesquisa UFRGS de 1993 a 1994, este número aumenta para 51 professores-auto $67 \%$ do $67 \%$ dos professores oficialmente ligados à instituição e quase $90 \%$ dos 62 professores ativos de sala de aula fazem pesquisa individual e publicam. Desde 1988, já chegam a seis os grupos de pesquisa oficialmente reconhecidos pelo CNPq. Dois são os nossos pesquisadores A1, contamos com um Mestrado cientificamente muito ativo, assim como multiplicam-se os trabalhos de iniciação científica de acadêmicos orientados por professores de nossa casa; de 3 trabalhos no I Salão para os 32 trabalhos inscritos em 1998, assim como dois prêmios Jovem Pesquisador e vários destaques e menções honrosas nesses dez anos de Salão. Este aumento quantitativo é acompanhado por uma crescente preocupação com a formação acadêmica dos professores, Doutores e Mestres, sensibilizados todos para a pesquisa científica.

${ }^{54}$ Assim ROSENAU, 1992, p. 50

Revista da Faculdade de Direito da UFRGS, v. 20, Outubro/2001 dos sentimentos, do discurso, à literatura ou à economia. ${ }^{55}$ Rejeitada a verdade jurídica, aberto o sistema do Direito, deslegitimado o Direi to e suas instituições, cria-se assim um vazio científico e uma desconfortante igualdade $\mathrm{ci}$ entífica dos discursos, todos iguais ${ }^{56}$ uma vez que todos sem base e subjetivados ou flexibilizados ${ }^{57}$ há uma grande dificuldade para os estudantes e professores identificarem e avaliarem a qualidade das pesquisas e suas contribuições à sociedade e ao Direito.

Esta crise da pós-modernidade é, en verdade, uma mudança na maneira de pensar o Direito a resultar um certo apatismo imobilismo em relação às novidades por part da maioria, combinado com um certo radicalismo por parte de minorias, face aos novos desafios da sociedade pós-moderna. É uma desconcertante crise de ideais e de valores, entre pluralismo e radicalismo de verdades, que tem grande influência no Direito e na pesquisa deste final de século. Como ensina Rosenau, ${ }^{58}$ o vazio e a insegurança nas ciências sociais são grandes: "Post-modernists reduce social science knowledge to the status of stories.. Post-modern methodology is postpositivist or anti-positivist. As substitutes for the 'scientific method', the affirmatives (postmodernists) look to feelings, personal experience, empathy, emotion, intuition, subjective judgment, imagination, as well as diverse forms of creativity and play."

...Como ensina Rosenau ${ }^{59}$, esta fragmentação e desconstrução não pode ser aceita totalmente, uma reação deve existir. Em outras palavras, para evitar o atual vazio do estudo do discurso é necessário um revival do sério estudo da filosofia do Direito. Para combater o vazio das formas metodológicas, é necessário revisitar a especificidade do conhecimento jurídico, ${ }^{60}$ aceitar as bases do Direito como procura do justo e valorizar mesmo seus métodos tradicionais e específicos. ${ }^{61}$ Para combater a guerrilha metodológica, é necessário defender o pluralismo de pesquisas e a tolerância científica, única forma de evitar que os radicais "antimodernos" acabem excluindo vários cientistas que poderiam dar alguma contribuição à criação de um Direito adaptado ao novo milênio. Em outras palavras, há que se superar a visão que o Direito em si, sua metodologia e seu discurso ou a economia seria o único objeto de pesquisa válido. Há que se defender a pesquisa em Direito como contribuição à ciência do Direito, contribuição à procura do justo e da solução dos problemas individuais e sociais atuais, não importando a sua linha de pensamento, se alternativa desdogmatizante, se tradicional ou se conservadora neo-liberal." 62
${ }^{55}$ Veja ROSENAU,1992, p.50 a 52: "Post-modernists in almost every field of the social sciences have been experimenting with a subjectless approach in their inquiries... Rejecting the subject permits them to shift the focus of the inquiry elsewhere..."

${ }^{56}$ ROSENAU,1992, p.77 e p. 89.

${ }^{57} \mathrm{FACHIN}$, Luiz Edson e CARNEIRO, Maria Francisca, Aspectos da avaliação institucional dos programas de pós-graduação em Direito: instrumentos e concepçóes, in Revista de Informação Legislativa, Brasília, ano 35, nr. 137, jan/mar 1998, p. 205.

${ }^{58}$ ROSENAU,1992, p. 91 e p.117.

${ }^{59}$ ROSENAU, 1992, p. 124.

${ }^{60} \mathrm{FACHIN/CARNEIRO,} \mathrm{p.} 205$.

${ }^{61}$ LARENZ, Karl, Methodenlehre der Rechtswissenschaft, 6.Aufl., Springer, Berlin, 1991,p. 6.

${ }^{62}$ Extratos de nosso artigo, "A Crise, p. 96 a 101

Revista da Faculdade de Direito da UFRGS, v. 20, Outubro/2001 
Parece-me, efetivamente, se vamos ser pós-modernos, sejamos pelo menos conscientes de nosso papel na evolução da ciência do Direito, sejamos ao menos pós-modernos afirmativos. ${ }^{63}$ É o momento do revival pós-moderno, plural e tolerannte, dos Direitos humanos refletir-se na própria academia e na liberdade científica de cada um, como forma de construção de uma teoria não-discriminatória e efetiva de harmonia social, teoria de inclusão científica para o Direito no novo século. Repito: O desafio neste início de século não é mais a simples inclusão da pesquisa jurídica nas ciências sociais, mas o seu desenvolvimento como efetiva contribuição à sociedade ${ }^{64} \mathrm{e}$ à Justiça , não ao cientificismo e à burocracia.

\section{II - Ensinando a pesquisar: $O$ Grupo de Pesquisa CNPq "Mercosul e Direito do Con- sumidor" e o desenvolvimen- to da metodologia de ensino da pesquisa "Sprechstunde"}

\section{A. Metodologia de pesquisa em grupo "Sprechstunde"}

Desenvolvi uma metodologia para ensinar a pesquisar e parar pesquisar em grupo, compilando influências alemãs e brasileiras, $o$ resultado final é mais uma experiência do que um caminho, um método, mas de qualquer maneira quero agora compartilhar este modelo de erros e acertos. Como antes observei, fui monitora na Faculdade de Direito da UFRGS, e ainda aluna pude colaborar com uma pesquisa quantitativa realizada pelo Prof. Dr. Michael R.

${ }^{63}$ ROSENAU, 1992, p. 57.

${ }^{64} \mathrm{GELLNER}$, Ernest, Pós-modernismo, Razão e Religião, Instituto Piaget, Lisboa , 1992, p. 60.

Revista da Faculdade de Direito da UFRGS, v. 20, Outubro/2001
Will, professor da Universidade de Saarbrücken, durante os seus seis meses de estadia em Porto Alegre. Estas duas experiências confirmaram minha vocação para ser professora e para continuar na pesquisa. A convite do Professor Will fui para a Alemanha, realizei um Mestrado e uma especialização e ainda tive a sorte e honra de ter sido sua pesquisadora-assistente por seis meses na Universidade de Saarlandes, assim como pesquisadora contratada por 3 meses no Instituto Max-Planck, de Freiburg im Breisgau, trabalhando com o Professor Hühnerfeld, além de ser colaboradora científica por três meses no Instituto Suíço de Direito Comparado, em Lausanne, trabalhando com o Professor Alfred von Overbeck. Ao retornar para o Brasil, queria compartilhar estes ensinamentos. Procurei basear-me nos modelos europeus que observei, adaptando-os à nossa realidade e necessidade.

A solidão da pesquisa, da elaboração dos trabalhos é inevitável. Aprendi, porém, que é possível crescer em conjunto, observando e compartilhando os trabalhos prévios de elaboração das produções científicas com os grandes mestres. Observei que de um talentoso "aprendiz" de pesquisa se pode fazer um brihante sucessor, e que vários aprendizes motivados mantém e renovam importantes escolas do pensamento. Efetivamente, eu própria aprendi muito com a precisão, rigorismo e sinceridade intelectual destes grandes professores-pesquisadores e fundar um grupo de pesquisa foi a maneira que encontrei para multiplicar estes ensinamentos. Desde minha entrada na Universidade Federal do Rio Grande do Sul, há 10 anos, tenho trabalhado em iniciação científica e pesquisa em grupo. Ao desenvolver uma metodologia própria para ensinar a pesquisar nomeie em sua homenagem, face à acessibilidade e à grandeza de meus mestres europeus: "Sprechstunde".

\section{Compilando influências ale- mãs e brasileiras para formar a "Sprechstunde"}

A monitoria é uma boa experiência para quem quer ser professor, mas a pesquisa é uma boa experiência para qualquer futuro profissional do Direito. A pesquisa é um elemento diferenciador, tão ou mais importante hoje, quando tantos estudam Direito e apenas passam nas Faculdades, como números à procura de um diploma autorizador do exercício de uma profissão. Saber pesquisar é um instrumento de criação de competência em Direito, é um caminho para a excelência e a especialização cada vez mais procuradas no mercado, é uma base a mais para a formação própria, a suṕrir falhas eventuais nos curricula das Faculdades ou os limites dos nossos próprios mestres e de nossas bibliotecas. Saber pesquisar é uma maneira para enfrentar qualquer desafio novo em Direito e a vida dos profissionais é uma constante renovação destes desafios.

Particularmente, considero que a pesquisa foi meu caminho de destaque e de excelência. Quando o professor Michael Will me convidou para com ele levantar e pesquisar todos os casos de adoção internacional em Porto Alegre nos últimos 5 anos, poderia ter dito "não", mas aceitei e isto me descortinou o mundo do Direito. Não há pesquisa em Direito Internacional, porém, sem conhecimento de línguas estrangeiras e neste caso, fui escolhida inicialmente por esta aptidão. ${ }^{65}$ Então no quarto ano da Faculdade tive o prazer de acompanhar o mestre de Saarbrücken, desde a elaboração das fichas de casos e formulários, das fichas de leituras e bibliográficas, até o fotocopiar de todas as fontes e os processos. Observei seu rigor e preciosismo, sua preocupação com os erros,

com a exatidão e exaustão das fontes. Esta primeira pesquisa com casos foi uma experiência impar, que muito me ajudou no futuro, especialmente na escolha de meus temas de Mestrado e Doutorado. Nada melhor para descortinar as perguntas importantes, do que saber o que acontece na prática e quais as falhas o nosso sistema legal ainda possui. Esta pesquisa ajudou-me muito também quando dos trabalhos de elaboração e crítica do Estatuto da Criança e do Adolescente, quando trabalhava na Consultoria Jurídica do Ministério da Justiça. Por ironia do destino, justamente a evolução e a mudança da lei brasileira de 1990 acabou por deixar inédito o trabalho resultado desta pesquisa. De outro lado, esta pesquisa quantitativa e qualitativa ajudou-me decivamente a abrir meus horizontes também para a interdiciplinariedade, pois tive a oportunidade de trabalhar durante um ano com as assistentes sociais e psicológas do então Juizado de Menores. ${ }^{66}$

Já na Alemanha, fui contratada como pesquisadora-junior no Instituto Max-Planck de Freiburg junto ao Prof. Dr. Peter Hühnerfeld. O Instituto, que consiste em uma maravilhosa $\mathrm{Bi}$ blioteca, realiza estudos para o governo alemão e pude participar de dois destes trabalhos de pesquisa, transformados mais tardes em livros, um sobre o aborto e a condição da mulher no Brasil e outro sobre a proteção do meio ambiente no Brasil. Aprendi que o simples levantamento bibliográfico e fichamento das obras já é um momento de grande crescimento para o aluno. Aprender a resumir, a criticar as obras por sua relevância, sua organização, suas notas ou pela origem de suas principais teses, é um valioso exercício, que poupa o tempo do pesquisador sênior (ainda mais em um Brasil que tudo se publica) e enriquece em muito, solidificando, os conhecimentos do pesquisador-júnior. Des-

${ }^{65}$ Assim também ARAÚJO, p. 29

${ }^{66}$ Minhas homenagens à assistente social Sylvia Nabinger, que realizou com os mesmos casos a pesquisa de seu doutorado na Faculdade de Direito de Lyon, França, por seu aopoio e modelo.

Revista da Faculdade de Direito da UFRGS, v. 20, Outubro/2001 
taque-se a sinceridade intelectual deste mestres alemães. Foi muito positivo poder observálos e ajudá-los a elaborar suas notas de rodapé, seu minucioso re-exame das fontes e organização lógica do pensamento. Os pesquisadoresjunior nada escrevem, mas tudo acompanham, e este acompanhar, inclusive em Congressos e em discussões de grupos de pesquisadores, são momentos de grande crescimento. Outro fator a destacar é a liberdade no trabalho de pesquisa, organizado nas horas (inclusive nos finais de semana) e espaços livres e "inspirados" do pesquisador-júnior. Há controle de tarefas, não de horas ou dedicação, que aparecem claras nos resultados concretos do levantamento.

Em Tübingen, tive o prazer de acompanhar o Professor Dr. Wolfgang Knutt Nörr em muitas de suas "Sprechstunden". Chamou-me muita a atenção como este grande historiador do Direito estava lá, todas as semanas, na mesma hora, a nossa disposição, junto com seus assistentes, para aconselhar e tirar dúvidas, para guiar-nos e repassar-nos literatura e tarefas como se isto fosse parte de uma missão. $O$ acesso ao professor-orientador é um fator de segurança. O contato com o mestre, o poder participar das reuniões de Cátedra e observar suas discussões e trabalhos com os assessores, enriquece o aluno. Outra boa experiência na Faculdade de Direito de Tübingen foi ter participado dos "Doktorseminaren", seminários onde os doutorandos expõem suas pesquisas para se submeter às críticas dos professores $\mathrm{e}$ assistentes. A mistura entre ambos, da graduação e da pós-graduação, agradou-me muito. ${ }^{67}$

Já mestre fui contratada para ser colaboradora científica do Instituto Suíço de Direito Comparado em Lausanne, podendo escrever um artigo (Prêmio van Calker), mas tendo que escrever pareceres de Direito Internacional
Privado junto ao Prof. Alfred von Overbeck. Instituto conta, ao total, com cerca de 10 colaboradores, que se reúnem regularmente com o professor coordenador, este e os colaboradores de todos os continentes escrevem juntos os livros do Instituto. Cada colaborador ou pesquisador tem seu tema individual, afeito a sua origem, sua língua materna, sistema jurídico ou religião, e assim todos trabalham com uma finalidade comum, mas individualmente e com pleme muito frutífero, pois estimula a cooperação e o trabalho em grupo, na convergência do objetivo comum, mas valoriza as individualidades e as origens diferentes (contávamos, por exemplo, em 1987, com especialistas sobre os sistemas socialistas, sobre China e Japão, sobre os países muçulmanos, sobre Israel, sobre Austrália e Oceania, sobre o sistema da common reito suíço e direitos da América-Latina).

Ao retornar para o Brasil, em 1988 após, em 1990, ao passar no concurso da Faculdade de Direito da UFRGS, procurei organizar algo semelhante, adaptado as nossas circunstâncias e contextos. Não posso porém deixar de mencionar a enorme influência que os anos de Doutorado, passados no Instituto de Direito Estrangeiro e Direito Internacional Privado da Universidade de Heidelberg, sob a coordenação do Prof. Dr. Dr. h. c. multi Erik Jayme, exerceram em mim. Neste Instituto, observei a preparação das reuniões de redação da Revista IPRAx, onde todos os 26 pesquisadores (seniores e juniores) do Instituto colaboram com material, traduções e artigos. Observei como organizavam em conjunto os congressos - as tradicionais festas de final de semestre- e seminários, como cooperam para cumprir com as tarefas distribuídas pelos 3 professores Diretores, como compartilham o conhecimento com seus "sucessores", sempre na procura da excena liberdade de opinião. Este método pareceulaw, sobre o direito alemão, direito francês, di-

${ }^{67}$ Assim também o testemunho de GUERRA, Willis,Critérios de avaliação e reconhecimento dos cursos de pósgraduação em Direito, Cad. Pós-Grad. Dir. UFPA, Belém, Ed. Especial, out.1999, p. 79

$\frac{\text { graduação em Direito, Cad. Pós-Grad. Dir. UFPA, Belém, Ed. Especial }}{\text { Revista da Faculdade de Direito da UFRGS, v. } 20 \text {, Outubro/2001 }}$ lência e da camaradagem. A organização de um Instituto como o de Heidelberg (que também é uma das mais excepcionais Bibliotecas que conheci) é o ideal de qualquer pesquisador.

Se o resultado final parece-se um pouco com tudo - e não é idêntico a nada que conheci -, resolvi nomear a metodologia com uma expressão alemã, justamente na esperança que fosse algo sólido e frutuoso, como o que observei. Queria bem marcar as influências que sofri: "Hora de aconselhamento", "hora da conversa", "hora de encontro" são algumas possíveis traduções desta expressão alemã que está na porta de cada professor, em cada Faculdade de Direito: "Sprechstunde".

A metodologia de ensino da pesquisa é simples. Repousa sobre três pilares básicos: a) liberdade acadêmica, b) uso positivo do interesse, das tarefas e dos erros, c) Aprender pesquisa, pesquisando e observando.

A liberdade acadêmica está retratada no grupo em dois aspectos: na liberdade do pesquisador-senior em escolher o assunto das pesquisas guarda-chuva e na liberdade de escolha dos temas individuais pelos pesquisadoresjuniores. $\mathrm{O}$ pesquisador-lider determina livremente o tema da pesquisa guarda-chuva, a depender de seu interesse ou necessidade momentânea, ele determina também as tarefas que deverão ser cumpridas pelos pesquisadores juniores e seus prazos, explicando-as. Receber uma tarefa é sinal de confiança no potencial do aluno. Quem pode participar naquela semana, manifesta-se e pede para colaborar, quem não

\section{O resultado final: a "Sprechstunde"}

pode cala ou manifesta o motivo porque não pode participar. Assim valoriza-se a tarefa e o grupo desenvolve uma dinâmica própria de ajuda àqueles que receberam uma tarefa e não podem a cumprir sozinhos. A reunião é toda conduzida pelo líder, que determina a ordem de temas a ser discutidos. Quando as reuniões semanais terminam, o líder coloca-se à disposição dos pesquisadores juniores para tratar de suas pesquisas individuais e aconselhá-los em suas dificuldades. ${ }^{68}$

O método usado distingüe-se de outros grupos de pesquisa por nunca impor leituras obrigatórias, referenciais teóricos ou discutir textos previamente lidos em conjunto. $\mathrm{O}$ crescimento do aluno de iniciação científica é fomentado individualmente, pela dinâmica de cooperação do grupo, pela reincidência das tarefas, nunca por condução do pensamento. Leituras dirigidas, reflexões coordenadas e em grupo dirigem e manipulam o interesse dos alunos, nivelando-os e igualando-os no pensamento O método "Sprechstunde" se assenta justamente na manutenção das diferenças e tendências individuais. Leituras são recomendadas individualmente e nunca discutidas em grupo. Naturalmente, porém, os participantes do grupo acabam por ler a produção intelectual dos professores que participam do grupo, por curiosidade e interesse, não, por imposição. O ritmo de leituras de cada um, o despertar de seus interesses próprios (mais filosóficos, mais ligados à prática, ao direito comparado etc.) é um dos objetivos do método.

A iniciação científica, nas pesquisas guarda-chuva, dá-se por observação, por construção própria e imitação, não é conduzida, nem o método é discutido ou revelado para os alunos, sendo a tarefa de condução metodológica
${ }^{68}$ Como ensina Jeniffer GORE,p. 12, citando Foucault, por vezes ser menos democrático, dar forma e dirigir a conduta dos indivíduos em formação pode ser positivo, pois "nesse sentido, é estruturar o campo possível de ação dos outros".,(GORE, Jeniffer, Foucault e Educação: fascinantes desafios, in SILVA, Tomaz Tadeu, O Sujeito da

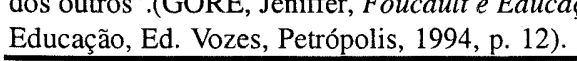

Revista da Faculdade de Direito da UFRGS, v. 20, Outubro/2001 
apenas do líder do grupo. Não há qualquer leitura metodológica indicada, nem qualquer discussão sobre o método entre aluno de iniciação científica e o professor-pesquisador, as leituras metodológicas nascem da necessidade sentida pelo aluno, que é então orientado.

A liberdade acadêmica do aluno se manifesta na escolha de seu tem a individual. Cada aluno, que participar das pesquisas guarda-chuva e das reuniões do grupo, deve escolher um tema, um aspecto, dentre os três tópicos possíveis: "Direito do Consumidor", "Mercosul", "Pós-modernidade jurídica". Cada aluno passa a pesquisar um tema individual, por ele livremente determinado, de acordo com a sua curiosidade, seu interesse e vocação individual. ${ }^{6}$ Neste tema ele prepara um pequeno trabalho oral de 10 a 20 minutos para ser apresentado nos Congressos Acadêmicos do Brasilcon (Instituto Brasileiro de Política e Direito do Consumidor), em caso de intercâmbio internacional (como aconteceu nos anos de 1996, 97, 98 e 99 com congressos acadêmicos organizados na Argentina e no Paraguai) e, especialmente, nos Salões de Iniciação Científica da UFRGS. Os salões de iniciação científica realizam-se há 12 anos na UFRGS, sempre em setembro. Há também o Salão preparatório da Faculdade de Direito da UFRGS, que se realiza, há quatro anos, sempre em agosto, organizado pela Comissão de Pesquisa da Faculdade (que atualmente coordeno) e o Centro Acadêmico André da Rocha. Este foi o pioneiro salão de uma unidade da UFRGS e tem como finalidade divulgar e

mapear a pesquisa na Faculdade, assim como treinar e desinibir os alunos para a apresentação principal na Universidade.

Há liberdade de determinação do tempo de dedicação à pesquisa, pois o importante é a realização da tarefa, não quando e como o aluno a cumprirá. Observei no Instituto Max-Planck que a determinação própria do tempo é uma excelente medida de disciplina e de adaptação. Cada um tem um ritmo para trabalhar e a pesquisa muitas vezes necessita de inspiração ou atenção redobrada. Poder pesquisar apenas uma hora por dia ou 5 horas corridas ou 2 noites na semana, vai depender de cada um e de suas tendências. Parece-me que não deve haver horários obrigatórios para a pesquisa ou para a presença do pesquisador na Universidade. A liberdade é também manifestada na presença não obrigatória nas reuniões do grupo. As reuniões e o contato mais íntimo com os professores-orientadores e mestrandos é um oferecimento. Se o aluno pode e quer aproveitar do oferecimento, excelente, se não, poderá mesmo assim pesquisar.

Especialmente com alunos que trabalham durante a graduação, dois caminhos são possíveis: ou os alunos mantém a comunicação por e-mail e participam das demais atividades do grupo (seminários, encontros, congressos) ou os alunos combinam com seus chefes poder participar de algumas reuniões. Muitos pesquisadores voluntários não tem bolsas de pesquisa, justamente pois fazem estágios ou já são

${ }^{69} \mathrm{Como}$ exemplo podemos observar a diversidade de temas escolhidos pelos alunos mais adiantados (pesquisadores-seniôres) este ano de 2000 nos Salóes de Iniciação Científica da UFRGS e da Faculdade de Direito: 1. Aspectos da Harma Publicidade Abusiva: sua regulamentação no Mercosul - Daniela Correa Jacques, 3. Serviços públicos essenciais e o princípio da continuidade: tutela do consumidor versus Estado-Fornecedor - Fernanda Girardi, 4. As várias nuances do dever de informar no Código de Defesa do Consumidor - Fernanda Nunes Barbosa, 5. Medicamentos genéricos: a liberdade de escolha do consumidor - Laura Ederich, 6. Cláusulas abusivas na Argentina e no Brasil Guillermo Campbell (UFRGS/Univ. de Cordoba, Argentina), 7. Fundamentos da proteção dos direitos da personalidade: a evolução da tutela do direito de imagem na jurisprudência do Tribunal de Justiça do Rio Grande do Sul ( 1984 a 2000) - Bruno Nunes Barbosa Miragem; 8. Internet e Direito - Antonia Espíndola Longoni Klee 9. Garantia globalizada: Análise de um possível leading case - Rafael Garcia; 10. Limitação de juros nos cartões de crédito- Odiléa Oliveira de Almeida Simão.

Revista da Faculdade de Direito da UFRGS, v. 20, Outubro/2001 concursados nos Tribunais. Como as reuniões do grupo são entre $12 \mathrm{~h} 30 \mathrm{~min}$ e 14 horas, quase todos que fazem estágios podem participar. A combinação entre prática e ensino da pesquisa em grupo tem sido muito exitosa, tanto que vários juizes do Rio Grande do Sul hoje dão preferência (ou convidam) os pesquisadores do nosso grupo para assessores, vários escritórios e grandes empresas de Porto Alegre e São Paulo nos telefonam pedindo "pesquisadores" do últimos anos e as cartas de recomendação do grupo têm aberto várias portas profissionais assim como permitido vantagens comparativa ao se concorrer por bolsas de estudo. O grupo oferece também pequenas aulas sobre metodologia da pesquisa, que são dadas pelos mestrandos e professores visitantes DAAD/ CAPES.

O uso positivo do interesse, das tarefa e dos erros, é uma tentativa de respeitar as individualidades e permitir que cada um desenvolva-se no seu ritmo e conforme suas inclinações temáticas (linguísticas e ideológicas). Todos os pesquisadores falam pelo menos uma língua estrangeira e entendem espanhol, que é considerada língua de trabalho no Rio Grande do Sul. $\mathrm{O}$ grupo facilita o acesso dos pesquisadores aos cursos de línguas, através do pedido de bolsas (principalmente de alemão) e recebe a colaboração constante do Instituto Goethe e do DAAD. ${ }^{70}$ As tarefas são valorizadas através da explicação de sua função: o aluno sabe então da importância do levantamento que vai fazer para a pesquisa guarda-chuva do professor ou do grupo, sabe se está procurando uma nota de rodapé ou uma recente crítica publicada da posição defendida do professor, de forma a demonstrar ao aluno como ele está colaborando com o pesquisador-senior. Os erros são critrutiva, mas a demonstrar a valorização do trabalho do aluno, pois se o erro persistir, o trabalho principal pode ser comprometido. Por exemplo, se o aluno fotocopia uma fonte e não indica a Revista da qual retirou o artigo, ou esquece de fotocopiar uma página, o erro será identificado pelo orientador, que pedirá para o aluno corrigir, explicando que assim a fonte está incompleta e não pode ser citada, o que a inutiliza. No Brasil, há certo receio em criticar e mostrar os erros, mas isto pode levar a uma repetição negativa. Na Alemanha, criticar é sinônimo de respeito e seriedade pelo trabalho alheio e próprio, leva ao crescimento, a melhoria. Errar é natural, e é um indício que o aluno se esforçou, está ativo, atuando, pesquisando. Só erra, quem faz. Quem erra, porque está iniciando e se desenvolvendo (em pesquisa), merece saber como acertar na próxima.$^{71}$

Mais do que funcional, o grupo deve servir para convívio. A aprendizagem passa pelo convívio. É o que distingue a escola da Universidade, que é fórum e lugar de convívio. Do modelo do hiwi alemão aprendi a beleza e prazer de conhecer e conviver mais intimamente com os grandes mestres. O grupo de pesquisa é uma maneira de conviver com o professor orientador, mas principalmente de encontrar, acompanhar e ajudar, durante sua estada na cidade, os professores convidados de fora. $\mathrm{Co}$ nhecer um importante professor estrangeiro, um professor de uma outra Universidade, um doutorando, um pesquisador associado é também o descortinar de novos horizontes, novos interesses, novos temas, nova bibliografia, novas idéias, é sobretudo , importante motivação modelo para se continuar a pesquisar, a querer saber sempre mais, a acompanhar este mundo

${ }^{70} \mathrm{Em} 2000$, receberam as bolsas de curta do duração DAAD para cursos de verão em alemão, na Universidade de Heidelberg e Freiburg, Rafael Garcia e Aline Jackisch.

${ }^{71}$ Veja sobre análise do erro (Fehleranalyse) na aprendizagem, EDMONDSON, Willis e HOUSE, Juliane, Einfïhrung in die Sprachlehrforschung, Ed. Francke, Tübingen, 1993, p. 205: "Fehler sind aus dieser Sichtweise also durchaus etwas natürliches, nämlich Indizien dafür, dass der Lerner sich aktiv mit [dem Objekt] auseinandersetzt."

Revista da Faculdade de Direito da UFRGS, v. 20, Outubro/2001 
que passa a estar ao alcance. Receber a tarefa de acompanhar, de ser o "Angel" do mestre visitante , pode determinar o lugar onde o estudante fará seu futuro mestrado e doutorado, pode mudar a perspectiva de vida do pesquisador-júnior. O convívio também deve se fazer no próprio grupo, por isso aprendi em Heidelberg que é preciso encontrar-se em outros momentos e tempos do que apenas na Universidade, especialmente em festas e comemorações.

O terceiro pilar é a prática da pesquisa: aprender, pesquisando. Se o Grupo de Pesquisa funciona como grupo de apoio e levantamento de fontes para os pesquisadores seniors e ao líder, ajudando na elaboração de seus trabalhos, produções científicas e acadêmicas, especialmente para preparar artigos de doutrina, livros, pesquisas quantitativas de jurisprudência, levantar novos leading cases, nova bibliografia e acompanhar a rapidez das modificações legislativas. O Grupo funciona, principalmente, como um laboratório de iniciação científica para os alunos, que assessoram as pesquisas principais (exceção feita à redação dos trabalhos, que é exclusiva dos pesquisadores-seniors), ${ }^{72}$ que levantam o material, discutem a sua relevância, precisão, orientação e atualidade, lêem e elaboram fichas de leituras individuais (do material selecionado como importante pelos pesquisadores seniors), observam as técnicas de delimitação, de precisão, de clareza, de sinceridade intelectual e de reflexão usadas pelos pesquisadores seniores, assim como passam a dominar os instrumentos técnicos da pesquisa (fichas de leituras, fichas de bibliografia, desenvolvimento de fichas de análise de casos, etc.) e instrumentos materiais (domínio dos acervos das Bibliote-

${ }^{72}$ Ao não permitir que os pesquisadores juniores elaborem qualquer texto, nem que ajudem nas pesquisas de Mestrado e Doutorado dos outros pesquisadores seniores, evita-se qualquer tipo de exploração de idéias e textos dos pesquisadores juniores e mantém-se a sinceridade intelectual de trabalhos exigida pelo modelo alemão, permitindo a sua participaçäo somente em algumas atividades básicas e que acompanhem os resultados e observem os métodos de cada pesquisador senior.

Revista da Faculdade de Direito da UFRGS, v. 20, Outubro/2001 e Direito do Consumidor", já com 9 anos de existência prática em Direito Internacional e Direito Comparado.

\section{Evolução e Estrutura atual do Grupo de Pesquisa CNPq "Mercosul e Direito do Con- sumidor"/UFRGS}

O Grupo de Pesquisa CNPq "Mercosul e Direito do Consumidor", que fundei e tenho a honra de liderar, completa agora 11 anos de experiência. Iniciou-se em fins de 1990, com alunos da minha primeira turma de Direito Internacional Privado na Faculdade de Direito da UFRGS, então formandos, com o mesmo método proposto, mas não frutificou. Comó na época era apenas Mestre e Especialista em Direito Comunitário Europeu, fazíamos parte do Grupo de Pesquisa sobre Mercosul liderado pela Profa Dra. Martha Olivar no PPGD da UFRGS, com um sub-projeto intitulado "Mercosul: Realidade Jurídica?", dentro da linha de pesquisa do PPGD/UFRGS "Integração como tarefa para ciência do Direito". Visava o grupo pesquisar apenas os temas momentosos de Direito Internacional Privado ${ }^{73}$ e do nascente Mercosul. ${ }^{74}$ nacionais, através da análise comparativa, da produção em conjunto e na diversidade atual; 2. A vocação intrínseca e estrutural do Direito Internacional, como matéria, e da pesquisa realizada neste campo do conhecimento refletir, desenvolver e ser instrumento da integração regional.

Como forma de unir e organizar estes dois temas usarei minha experiência como líder e fundadora do Grupo de Pesquisa CNPq "Mercosul

${ }^{73}$ Este projeto de Pesquisa, na linha de pesquisa "Integração como tarefa para a ciência do Direito" e teve três fases intituladas: 1991/92- Fase I: Contratos Interhacionais e Mercosul/Circulação de bens, $1992 / 93$-Fase II:Contratos Internacionais e Mercosul/Circulação de pessoas; 1993/94- Fase III: Proteção do Consumidor no Mercosul.

${ }^{74}$ Este projeto de Pesquisa intitulado "Integração do Cone Sul - Realidade Jurídica ?" teve apenas duas fases: 1991Fase I - Mercosul - Aspectos Jurídicos; 1992-1994- Fase II- Mercosul- Realidade Jurídica.

${ }^{75} \mathrm{Os}$ trabalhos individuais apresentados em 1992 tinham como temas: 1. Mercosul e Harmonização: Política de Transportes (Ana Inês Algotarta Latorre); 2. Mercosul - Realidade Jurídica (Luiz Carlos Hagmann); 3. O Contrato de Transporte Internacional de Cargas no contexto da integração Latinoamericana (Sabina Cavalli); 4. O papel do projeto de Código de Conduta da ONU sobre transferência de tecnologia nos países em desenvolvimento (Elaine Ramos da Silva).

${ }^{76}$ Os trabalhos individuais de pesquisa apresentados no Salão de Iniciação Científica da UFRGS, em 1993, tinham

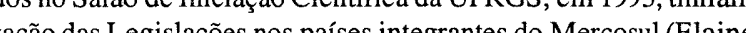
Ras Silva); 2. Respection Ramos no Mercosul (Fabiana d'Andrea Ramos); 4. Direito Internacional Privado - O casamento e as novas uniões (Ana Inês Latorre); 5. Relações de Sucessão no Mercosul (Sabina Cavalli). 
Em 1994, em virtude da saída dos quin- até março de 1996, o grupo ficou sob a coordeto-anistas, resolvi reformular novamente os projetos direcionando-os apenas para a pesquisa em temas envolvendo o Mercosul e o Direito do consumidor interno, de forma a permitir que alunos dos primeiros anos participassem do grupo. Novamente fomos premiados e o grupo renovou-se, ${ }^{77}$ mas como retornei para a Alemanha em fins de 1994 e lá escrevi meu Doutorado nação da Profa. Dra. Martha Olivar.

Com o meu Doutorado em $1996,{ }^{78}$ resolvi formalizar o Grupo e minha posição de pestrutura e o nome atual "Mercosul e Direito do Consumidor". Desde então o Grupo tem sido muito ativo e de 1996 a $2001^{79}$ recebeu mais 25 prêmios de pesquisa de iniciação científiquisador líder junto ao CNPq, dando-lhe a es-

${ }^{n}$ Os trabalhos individuais de pesquisa apresentados no Salão de Iniciação Científica da UFRGS, em 1994, tinham como títulos:1. A informática e o Direito à Privacidade (Angela Dumerque); 2. Direito de Arrependimento no Código de Defesa do Consumidor (Clarissa Costa de Lima); 3. A nova concepção de oferta e clausulas abusivas no CDC (Elaine Ramos da Silva), 4. Os contratos de adesão e as cláusulas abusivas sob a perspectiva do CDC (Ana Letícia Fialho); 5. O sistema de solução de controvérsias no Mercosul (Pedro Montenegro); 6. O dever de informar e a publicidade no CDC (Fabiana D'Andrea Ramos).

${ }^{78}$ Os trabalhos individuais de pesquisa, apresentados no Salão de Iniciação Científica da UFRGS, em 1996, tinham como títulos: 1. O direito da Concorrência no Mercosul (Pedro Montenegro); 2.Mercosul: Arcabouço jurídico e políticas universitárias (Fabio Morosini); 3.Meio ambiente e consumidor (Ana Letícia Fialho); 4. Importância do de Lima); 6. A responsabilidade civil por dano ambiental (Jesus Tupã Silveira Gomes).

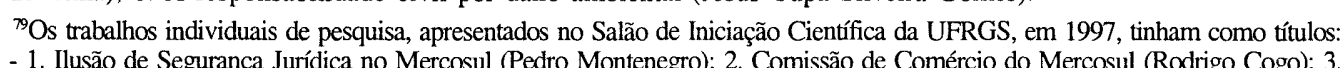
- 1. Ilusão de Segurança Jurídica no Mercosul (Pedro Montenegro); 2. Comissão de Comércio do Mercosul (Rodrigo Cogo); 3. Contratos à distância e a proteção do consumidor (Ariane Freitas); 5. Quantificação do dano moral: determinaç̃o de critérios (Patrícia Peressutti); 6. O conceito de consumidor no CDC (Fernanda Barbosa); 7. Contratos de Seguro-Saúde e o Código de Defesa do Consumidor (Alberto Franco); 8. Direito do consumidor de serviços médicos (Giovanna Maciel); 9. Reconhecimento de Paternidade: Um estudo paralelo entre Brasil e Argentina (Fábio Costa Morosini). Os trabalhos individuais de pesquisa apresentados no Salão de Iniciação Científica da UFRGS, em 1998, tinham como títulos: 1. A publicidade enganosa e abusiva no CDC e suas tendências (Aline Jackisch); 2. Consumo sustentável e o Direito do Consumidor (Bárbara Garcia); 3. Novo regime das incorporaçoes imobiliárias e o CDC (Fernanda Barbosa); 4. A responsabilidade civil no CDC pelo fato do produto e pelo vício do produto (Fabiano Menck); 5. O atual direito do consumidor de serviços no Brasil (Giovana Maciel) 6. O consumidor equiparado. reflexos nos serviços bancários (Fábio Morosini); 7. Contratos à distância e perspectivas de harmonizaçã̃o pesquise (Apresentados no Saño de Inicicoñ Científica Comércio no Mercosul (Rodrigo Cogo). Os trabalhos individuais de de pesquisa apresentados no Salão de Iniciação Científica da UFRGS, em 2000, tinham como títulos: 1 . A spectos da Harmonização do Direito Societário na União Européia: Um exemplo para o Mercosul (Lucas Faria Annes); 2. Publicidade Abusiva: sua regulamentação no Mercosul (Daniela Correa Jacques) 3. Serviços públicos essenciais e o princípio da continuidade: tutela do consumidor versus Estado-Fornecedor (Fernanda Girardi) 4 . As várias nuances do dever de informar no Código de Defesa do Consumidor (Fernanda Nunes Barbosa) 5. Medicamentos genéricos: a liberdade de escolha do consumidor (Laura Ederich) 6. Cláusulas abusivas na Argentina e no Brasil - Guillermo Campbell (UFRGS/Univ. de Cordoba, Argentina); 7. Fundamentos da proteção dos direitos da personalidade: a evolução da tutela do direito de imagem na jurisprudência do Tribuna de Justiça do Rio Grande do Sul (1984 a 2000) (Bruno Nunes Barbosa Miragem); 8. Garantia globalizada: Análise de um possível leading- case (Rafael Garcia); 9. Limitação de juros nos cartões de crédito (Odiléa Oliveira de Almeida Simão). Os trabalhos individuais de pesquisa que serão apresentados no XIII Salāo de Iniciação Científica da UFRGS, que ocorrerá entre os dias 03 e 07 de dezembro próximo, têm como títulos: 1. A Homologação de Sentenças Arbitrais Estrangeiras pelo Supremo Tribunal d'Azevedo); 3. A Proteção dos Consumidores nos Contratos Eletrônicos (Antonia Espíndola Lon Longi Klee); 4 . Alimentos Transgênicos: Ética, Consumo e Meio Ambiente (Laura Oliveira Ederich); 5. Aspectos Jurídicos do "Recall"); e sua Introduç̃o no Direito Brasileiro (Lucas Faria Annes); 6. Análise Crítica do Caso Colgate/Kolynos (Lúcia Carvalhal Sica); 7 . Aspectos Jurídicos da Proteção aos Programas de Computador com Código-Fonte Aberto no Brasil (Maitê de Souza Schmitz); 8.0 Código de Defesa do Consumidor enquanto Lei de Função Social (Marilia Zanchet); 9 . Os Contratos de Previdência Privada e o Código de Defesa do Consumidor (Odiléa Oliveira de Almeida Simão); 10. O Uso da Internet para a Aquisição de Bens e Serviços: alternativa segura? (Rafael Barreto Garcia); 11. Posição Imutâvel do Superior Tribunal de Justiça: A Questão da Importação de Merluzas (Rafael Pellegrini Ribeiro); 12. Comparação Principiologica entre a Affirmative Action e o Código de Defesa do Consumidor (Ricardo Medeiros de Castro); 13. Responsabilidade do Transportador Aéreo por Extravio de Bagagem (Tatiana de Campos Aranovich); 14. O Cartel de Preços e a Defesa do Consumidor (Thales Gonçalves Dell Giustina); 15. As linhas gerais da responsabilidade pelo fato do serviço no CDC e sua recep̧̧ão ou não pelo Tribunal de Justiça a de do Sul - (Thomaz Francisco Silveira de Araújo Santos) ca ${ }^{80}$ incluindo, na área de Ciências Sociais com o trabalho individual: "Comunicação Aplicadas, novamente o PRÊMIO JOVEM de Massa: implicações legais das PESQUISADOR UFRGS, em $1999,{ }^{81} \mathrm{com}$ o trabalho do Pesquisador e Bolsista FAPERGS Fábio Costa Morosini, que mereceu o prêmio máximo do Salão da UFRGS tecnologias emergentes".

O Grupo de Pesquisa $\mathrm{CNPq}$ "Mercosul e Direito do Consumidor", atualmente congrega 12 alunos de graduação

${ }^{80}$ Os prêmios recebidos pelos integrantes do Grupo, em iniciação científica, foram: 1. Pesquisadora PROPESPUFRGS Patrícia Peressutti, DESTAQUE no XI Salão de Iniciação Científica UFRGS e CNPq, Seção III, 1997 2. Pesquisadora FAPERGS Giovana Maciel (PUC), DESTAQUE no IX Salão de Iniciação Científica UFRGS e CNPq, Seção III, 1997 . 3. Pesquisador CNPq/UFRGS Pedro Montenegro- 2. PREMMIO no I Salão de Iniciação Científica da Faculdade de Direito/UFRGS, Bolsa de estudo do Mestrado em Direito/UFRGS para 1998. 4. Pesquisadora CNPq/
UFRGS, Bárbara S. Garcia, DESTAQUE no I Salão de Iniciação Científica do Direito, Faculdade de Direito UFRGS, UFRGS, Bárbara S. Garcia, DESTAQUE no I Salão de Iniciação Científica do Direito, Faculdade de Direito UFRGS,
1998 .5. Pesquisadora CNPq/UFRGS, Ariane Cunha Freitas, DESTAQUE no I Salão de Iniciação Científica do 1998 . 5. Pesquisadora CNPq/UFRGS, Ariane Cunha Freitas, DESTAQUUE no I Salão de Iniciação Cientifica do
Direito, Faculdade de Direito UFRGS, 1998. 6. Pesquisador voluntário Fabiano Menck, UFRGS, DESTAQUE no X Salão de Iniciação Científica UFRGS e CNPq, Ciências Sociais Aplicadas, 1998 . 7. Pesquisadora voluntária Cláudia Travi Pitta Pinheiro - 2. PRÊMIO no III Salão de Iniciação Científica da Faculdade de Direito/UFRGS, 1999, Bolsa de estudo do Mestrado em Direito/UFRGS para 2000. 8. Pesquisadora CNPq/PIBIC Aline Jackisch, Co-orientador o Prof. Sérgio José Porto, DESTAQUE no III Salão de Iniciação Científica do Direito, Faculdade de Direito UFRGS, 1999. 9. Pesquisadora CNPq/PIBIC Laura Oliveira Ederich, DESTAQUE no III Salão de Iniciação Científica do Direito, Faculdade de Direito UFRGS, 1999.10. Pesquisadora PROPESQ/UFRGS Rosaura Macagnan Viau, DESTAQUE no III Salão de Iniciação Científica do Direito, Faculdade de Direito UFRGS, 1999.11. Pesquisador PROPESQ/UFRGS Bruno Nunes Barbosa Miragem, DESTAQUE no III Salão de Iniciação Científica do Direito, Faculdade de Direito UFRGS, 1999. 12. Pesquisadora voluntária Odiléia Oliveira de Almeida Simão,
DESTAQUE no III Salão de Iniciação Científica do Direito, Faculdade de Direito UFRGS, 1999. 13. Pesquisador DESTAQUE no III Salão de Iniciação Científica do Direito, Faculdade de Direito UFRGS, 1999. 13. Pesquisador Fociais Aplicadas, 1999 .14. Pesquisadora voluntária Fernanda Nunes Barbosa (PUC), DESTAQUE no XI Salão de Iniciação Científica UFRGS e CNPq, Ciências Sociais Aplicadas, 1999. 15. Pesquisador CNPq/PIBIC Aline Jackisch, Co-orientador o Prof. Sérgio José Porto, DESTAQUE no XI Salão de Iniciação Científica UFRGS e CNPq Ciências Sociais Aplicadas, 1999. 16. Pesquisador FAPERGS Fábio Costa Morosini (PUC), PRÊMIO JOVEM PESQUISADOR do XI Salão de Iniciação Científica UFRGS e CNPq, Ciências Sociais Aplicadas, 1999. 17. Pesquisadora voluntária, ex-CNPq/PIBIC, Laura Oliveira Ederich, DESTAQUE no IV Salão de Iniciação Científica do Direito, Faculdade de Direito UFRGS, 2000. 18. Pesquisador PROPESQ/UFRGS, Bruno Miragem, DESTA QUE no IV Salão de Iniciação Científica do Direito, Faculdade de Direito UFRGS, 2000.19. Pesquisadora voluntária, Daniela Jacques, DESTAQUE no IV Salão de Iniciação Científica do Direito, Faculdade de Direito UFRGS, 2000. 20. Pesquisadora voluntária, Fernanda Giradi, DESTAQUE no IV Salão de Iniciação Científica do Direito,
Faculdade de Direito UFRGS, 2000. 21. Pesquisador CNPq/UFRGS, Rafael Garcia, DESTAQUE no IV Salão de Iniciação Científica do Direito, Faculdade de Direito UFRGS, 2000. 22. Pesquisadora voluntária, Antônia Klee, DESTAQUE no IV Salão de lniciaça Científica do Direito, Faculdade de Direito UFRGS, 2000. 23. Pesquisadora CNPq, Ciências Sociais Aplicadas, 2000 .24. Pesquisador PROPESQ/UFRGS, Bruno Miragem, DESTAQUE no XII Salão de Iniciação Científica UFRGS e CNPq, Ciências Sociais Aplicadas, 2000 . 25. Pesquisador CNPq/UFRGS, Rafael Garcia, DESTAQUE no XII Salão de Iniciação Científica UFRGS e CNPq, Ciências Sociais Aplicadas, 2000 . Em 2001 rectemos dois destaques internacionais: primeiro lugar no Brasil na Eliminatoria nacional realizada $\mathrm{n}$ UFSC do Philip C. Jessup International Law Moot Court Competition/2001, participação em Washington, D.C. Estados Unidos, com Professores Cláudio Moretti e Manoel André da Rocha), e estudantes do grupo: Ana Gerdau de Borja ; Thomaz Francisco Silveira de Araújo Santos Maitê de Souza Schmitz, Ricardo Medeiros de Castro. Prêmio de Melhor Delegado, representando o Canadá, no Comitê de Direitos Humanos, no IV Americas Model United Nations (AMUN), realizado em Brasília, D.F, entre 14 e 19 de julho de 2001 para Thomaz Francisco de Araújo Santos.

${ }^{81}$ Os trabalhos individuais de pesquisa apresentados no Salão de Iniciação Científica da UFRGS, em 1999, tinham como títulos: 1. A cláusula de indexação no contrato de leasing e o consumidor- Laura Oliveira Ederich; 2. A garantia como pós-venda no direito do consumidor- Rafael B. Garcia; 3. O prazo de carência nos contratos de incorporação imobiliária - Fernanda Nunes Barbosa; 4. A prestação de serviços educacionais à luz do direito do consumidor - Carina Bonzanini da Silva; 5. O Bug do milênio e seus reflexos para o consumidor - Roberto Silva da Rocha; 6. Multipropriedade - Rosaura Macagnan Viau; 7. A problemática dos serviços prestados através das linhas
0900 - Odiléia Oliveira de Almeida Simão; 8. O Plano Nacional de Desestatização e o consumidor - Bruno Nunes 0900 - Odiléia Oliveira de Almeida Simão; 8. O Plano Nacional de Desestatização e o consumidor - Bruno Nunes
Barbosa Miragem; 9. A agência estadual de regulação dos serviços públicos delegados do Rio Grande do Sul -
AGERGS e o consumidor - Cláudia Travi Pitta Pinheiro;10. As sociedades comerciais no Mercosul - Simone Stabel Daudt. 11. Comunicação de Massa: implicações legais das tecnologias emergentes - Fábio Costa Morosini.

Revista da Faculdade de Direito da UFRGS, v. 20, Outubro/2001 
da Faculdade de Direito da UFRGS, ${ }^{82} 3$ alunos da Faculdade de Direito da PUC/RS, ${ }^{83}$ uma aluna estrangeira (convênio) ${ }^{84}$, seis mestrandos do PPGD/UFRGS,${ }^{85}$ que realizam na co-orientação do grupo, como parte de sua "atividade docente", um doutorando, que oriento e uma economista, especialista em regulação, e na co-orientação, contamos até o mês de janeiro de 2001, com um jovem professor alemão, o docente de longa duração DAAD/CAPES ${ }^{86}$ lotado na Faculdade de Direito da UFRGS e com professores convidados estrangeiros ${ }^{87}$ por curto período, assim como com professores brasileiros e mestrandos de outras instituições, ${ }^{88} \mathrm{e}$
${ }^{82}$ Atualmente fazem parte do grupo, que se reúne sempre as terças feiras na sala de aula da Biblioteca Depositária da Organização das Nações Unidas (ONU), na Faculdade de Direito da Universidade Federal do Rio Grande do Sul, os seguintes alunos: Ana Gerdau de Borja, Ana Rispoli d'Azevedo, Antonia Espíndola Longoni Klee, Laura os seguintes alunos: Ana Gerdau de Borja, Ana Rispoli d'Azevedo, Antonia Espíndola Longoni Klee, Laura
Oliveira Ederich, Lucas Faria Annes, Lúcia Carvalhal Sica, Maitê de Souza Schmitz, Marília Zanchet, Odiléa Oliveira Ederich, Lucas Faria Annes, Lúcia Carvalhal Sica, Maitê de Souza Schmitz, Marilia Zanchet, Odiléa de Campos Aranovich, Thales Gonçalves Della Giustina e Thomaz Francisco Silveira de Araújo Santos.

${ }^{83}$ Ana Rispoli d'Azevedo, Lúcia Carvalhal Sica e Tatiana de Campos Aranovich, Faculdade de Direito da Pontifícia Universidade Católica, PUC/RS, Porto Alegre.

${ }^{84} \mathrm{Já}$ participaram do grupo os seguintes alunos estrangeiros: No ano letivo de 1996, o aluno alemão Christian Schindler, aluno então matriculado na Universidade de Heidelberg, Alemanha, hoje assistente do Prof. Dr. Erik Jayme, no Instituto de Direito Estrangeiro e Direito Internacional Privado da Univ. de Heidelberg, justamente por seu conhecimento do Direito brasileiro. O Doutorando Schindler, que recebeu na época crédito educativo do governo alemão para sua estada na UFRGS, é o secretário da Associação de Juristas Luso-Alemã da Univ. de Heidelberg e coordenou a ida de alunos do grupo para a Alemanha, como o mestrado de Fabiana D'Andrea Ramos na Universidade de Heidelberg, e os cursos de verão en Garcia e Aline Jackisch. No ano de 2000, por dois meses, duas alunas da Universidade conveniada de Santa Fé (Argentina). Este Intercâmbio de estudantes da graduação da Faculdade de Direito da Universidad Nacional del Litoral, Argentina, por dois meses na Faculdade de Direito da UFRGS, para assistir aulas e pesquisar sobre Direito do Consumidor, em maio/junho 2000, foi uma experiência muito positiva para o grupo e foi financiando pela UNL, que deu prêmios de pesquisa às duas estudantes, e esperamos que se repita em 2001. Atualmente, temos acompanhado a estada de Helene Heyd, aluna de Relações Internacionais da Universidade de Berlim, Alemanha.

${ }^{85}$ Atualmente Fernanda Nunes Barbosa, Daniela Correa Jacques, Michele Costa da Silveira, Bruno Nubens Barbosa Miragem, Cristiano Heineck Schmidt e José Salvador Cabral Marks., PPGD/UFRGS.

${ }^{86}$ Até o mês de janeiro do ano de 2001 tivemos o acompanhamento e orientação do Dr. Ulrich Wehner, professor convidado UFRGS, DAAD/CAPES, oriundo da Universidade de Colônia, Alemanha e indicado pela Universidade de Heidelberg, conveniada com a UFRGS, mas antes contamos por 2 anos com o acompanhamento da Dra. Harriet Christiane Zitscher, do Instituto Max-Planck em Hamburgo (Alemanha), professora convidada UFRGS/ DAAD/CAPES, nesta cátedra alemã na Faculdade de Direito de 1998 a 1999.

${ }^{87}$ Entre junho e outubro de 2000 tivemos a colaboração do pesquisador do Centre de Droit de la Consommation da Universidade Católica de Louvain-la-Neuve, Bélgica, o Mestre alemão Jens Karsten, enviado pelo Prof. Dr. Thierry Bourgoignie para pesquisar sobre a proteção do consumidor no Mercosul. Tentamos enviar nossos mestrandos para o mesmo intercâmbio no Centre, mas não obtivemos financiamento. O Intercâmbio de Mestrandos do Grupo de Pesquisa CNPq "Mercosul e Direito do Consumidor"/UFRGS com pesquisadores do Centre de Droit de La Consommation da Universidade de Louvain-la-Neuve, Bélgica, em estágios de pesquisa de 4 meses, iniciouse com a vinda do Me. Jens Karsten.

${ }^{88}$ Os hoje jovens professores das Faculdades de Direito de Porto Alegre, os hoje mestrandos e especializandos,que tem sua origem como pesquisadores do grupo, costumam acompanhar as reuniões do grupo e colaborar na orientação dos mais jovens em seus temas de especialização, assim hoje colaborarm com o Grupo as professoras Fabiana D'Andrea Ramos (PUC/RS), Elaine Ramos da Silva (UFSM/RS), Sandra Lima Alves (CEUB/Brasilía), Sabina Cavalli (Católica/CE). Assim também colaboram os especializandos: Fabiano Mencke, Roberto Silva, Gustavo Aguiar, Alberto Franco, os mestrandos Cláudia Pitta Pinheiro (UFRGS) e Evelena Boenning (UFRGS) e o doutorando Fábio Costa Morosini, University of Texas, Austin.

Revista da Faculdade de Direito da UFRGS, v. 20, Outubro/2001 com 2 colegas professoras da Faculdade de Direito da UFRGS. ${ }^{89}$

\section{Relações institucionais, inter-institucionais e com a sociedade}

A UFRGS mantêm vários convênios, ${ }^{90}$ a Faculdade de Direito ${ }^{91}$ também, mas o grupo mantém contatos próprios e menos formais, além destes já formalizados, especialmente com o Instituto Brasileiro de Política e Direito do Consumidor (São Paulo), algumas cátedras da UBA da Universidade de Rosário e de Santa Fé (Argentina), com a UROU de Montevidéu, com o Centre de Droit de la Consommation, na Bélgica, com o Instituto de Direito Internacional Privado da Universidade de Heidelberg, mais recentemente com a Universidade de Bremen na Alemanha, com o Centre de Recherches Européeennes da Université de Rennes I, na
França, com o Center of Comparative Law da Universidade de Baltimore, com o Texas International Law Jornal da Universidade do Texas-Austin, USA.

O Grupo de Pesquisa participa ativamene do Departamento Acadêmico do Brasilcon, Instituto Brasileiro de Política e Direito do Consumidor, uma organização não-governamental de caráter científico, criada pelos autores do Código de Defesa do Consumidor para estudar a eficácia desta lei e controlar a sua manutenção no mercado brasileiro. A colaboração com Brasilcon se concretiza de várias formas. Em primeiro lugar, através de publicações, trabalho que foi iniciado com a organização do congresso e após do livro que coordeno "Estudos sobre a proteção do Consumidor no Brasil e no Mercosul", publicado em 1994 pela Editora Livraria dos Advogados, de Porto Alegre.

Especialmente, depois volta de meu doutorado, o grupo passou a realizar traduções do francês, ${ }^{92}$ alemão ${ }^{93}$, inglês ${ }^{94}$ e espanhol ${ }^{95}$ para

${ }^{89} \mathrm{As} \mathrm{colegas} \mathrm{que} \mathrm{colaboram} \mathrm{nas} \mathrm{publicações} \mathrm{coletivas} \mathrm{do} \mathrm{grupo,} \mathrm{na} \mathrm{organização} \mathrm{de} \mathrm{congressos} \mathrm{e} \mathrm{eventos} \mathrm{do} \mathrm{grupo}$ o grupo em suas viagens ao exterior sao as colegas Martha Olivar Gimenez (UFRGS-PPGD e PUC/RS). bolsista pelo Prof. Me. Sérgio José Porto (UFRGS).

${ }^{\circ} \mathrm{O}$ grupo utilizou os convênio da UFRGS até agora com a Universidade de Heidelberg, Tübingen, Kiel na Alemanha, UBAArgentina, Universidad Nacional de Córdobae Universidad Nacional del Litoral, na Argentina, Universidade de Baltimore, nos EUA, Universidad Nacional de Assunción, Paraguai, e Universidad da República, Uruguai.

${ }^{91}$ A Faculdade de Direito e o PPGD possuem convênios com a Universidade de Münster, Alemanha, Universidade de Paris I (Panthéon- Sorbonne), Universidad Nacional de Rosário, Argentiña e USP, São Paulo.

${ }^{92}$ Assim os artigos de Alfred von Overbeck (Instituto Suiço de Direito Comparado), "Eleição de Foro segundo a nova lei suíça sobre Direito Internacional Privado de 18 de dezembro de 1987", in Revista da Faculdade de Direito da UFRGS, vo. 12,1996, p. 7 a 18 e artigo do Prof. Bernard Dutoit.

${ }^{93}$ Tradução do artigo de Michael R. Will (Instituto Europa, Saarbücken), A experiência de harmonização das legislações na Europa-Harmonização Autônoma?, executada por Elaine Ramós da Silva e publicada na Revista da Faculdade de Direito da UFRGS, vol. 13, 1997, p. 207-234. e tradução executada pela líder do grupo do capítulo do livro de Eike von HIPPEL, "Verbraucherschutz" e publicada na Revista Direito do Consumidor, São Paulo, vol. 1,pg. 7 a 15:"A proteção do consumidor-comprador" e também a tradução de artigo do alemão para o português do Prof. Dr. Dr. h.c. Erik Jayme, com 31 pgs., publicada na Revista dos Tribunais nr. 759, janeiro 1999, p.24 a 40, sobre o tema:"Visões para uma teoria pós-moderna do Direito Comparado".

${ }_{94}$ Tradução do artigo de J.H.A. van Loon, do inglês para o português, "Os Aspectos Legais da Adoção internaci"Tradução do artigo de J.H.A. van árion, da Associação de Direito Internacional", publicada no livro : -Homenagem à Carlos Henrique de Carvalho, Ed.Revistas dos Tribunais, São Paulo, 1995, pg. 241ss

${ }^{95}$ Veja tradução executada pela lider do grupo, para o português de artigo em espanhol do Prof. Rúben S. Stiglitz (Universidad de Buenos Aires), publicado na Revista Direito do Consumidor, São Paulo, vol. 13, jan/março 1995,

pg. 5 a 11, com o título: "Aspectos Modernos do Contrato e da Responsabilidade Civil" 
o português e publicar na Revista do Basilcon (Revista Direito do Consumidor) e também na Revista da Faculdade de Direito UFRGS. Também organizamos e publicamos colaborações em espanhol de nossos "correspondentes estrangeiros", ${ }^{96}$ especialmente nossos professores visitantes argentinos. ${ }^{97}$ Quanto à editoração de Revistas Jurídicas, inicialmente, de 1992 a 1998, ajudamos o Herman Benjamin, presidente e fundador do Brasilcon, ${ }^{98}$ na editoração da Revista Direito do Consumidor. Ao assumir a editoração da Revista, em 1998, criamos uma onde continuamos a publicar, em espanhol, trabalho pioneiro e inovador de Antônio seção especial para doutrina internacional,

${ }^{96}$ Assim publicamos os trabalhos dos jovens professores e pesquisadores estrangeiros que se correspondem com o grupo, Diego Fernandez Arroyo, argentino, professor na Univ. de Autonoma Madri (Sobre la existência de una família jurídica latinoamericana, in Revista da Faculdade de Direito da UFRGS, vo. 12, 1996, p. 93 a 110), Gilles Cistac, francês, Diretor da Univ. de Maputo, Monçambique (Poder Legislativo e Poder regulador na Constituição Moçambicana de 30 de novembro de 1990, in Revista da Faculdade de Direito da UFRGS, vo. 12, 1996, p. 148-160), Christoph Benicke, alemão, assitente na Universidade de Heidelberg ( La convención sobre los derechos del niño de las naciones unidas y la reforma del derecho de custodia y de visita en Alemania, , in Revista da Faculdade de Direito da UFRGS, vo. 13, 1997, p. 5170), Erasmo Marcos Ramos, brasileiro, mestrando na Universidade de Heidelberg, Alemanha (A influência do BGB na parte geral do novo Código Civil português, in Revista da Faculdade de Direito da UFRGS, vol. 15,1998 , p. 75-98).

${ }^{97}$ Veja os artigos de Carlos Alberto Ghersi (UBA) publicados na Revista da Faculdade de Direito da UFRGS (La contracción entre la reformulación de la categoria juridica del daño resarcible y ele acceso al daño resacible en el final del siglo XX, in vol. 11,1996, p. 24-39 e Posmodernidad juridica- el analisis contextual del Derecho como contracorriente a la abstracción juridica, in vol. 15, 1998, p. 21-32) e na Revista Direito do Consumi Direito da UFR (La descodificación y fractura del Decho Civil, in vol.11,1996, Contractuales, in Revista da Faculdade de Direito da UFRGS, vo. 16, 1999, p. 161-202) e na Revista Direito do Consumidor e apresentação do livro de Lorenzetti publicado pela Editora Revista dos Tribunais (Fundamentos do Direito Privado), Maria Blanca Noodt Taquela (UBA), publicado na Revista da Faculdade de Direito da UFRGS, vol. 15, 1998, p. 181-192, Atílio Alterini (UBA), Informe sobre la Responsabilidad Civil en el Proyecto de codigo Civil de 1998,vol. 17, 1999, p. 3 e seg. e os publicados na Revista Direito do Consumidor.

${ }^{98}$ Assim foram publicados de nossos correspondentes, por inicativa do Dr. Benjamin, na Revista Direito do Consumidor (RT, São Paulo), os seguintes trabalhos: Gabriel Stiglitz "O direito contratual e a proteção jurídica do consumidor". RDC n. 01, p. 184-199, "O Direito do Consumidor e as práticas abusivas Realidade e perspectivas na Argentina" RDC n.03, set/dez 1992, p. 27-35 e "Las acciones colectivas en proteccion del consumidor"RDC n. 15, jul/set 1995, p. 20-27. Rúben S. Stiglitz “Aspectos modernos do contrato e da responsabilidade civil" RDC n. 13, ja/mar 1995, p. 5-11. Ricardo Luiz Lorenzeti "Analisis crítico de la autonomia privada co "Clterini "Os contratos de consumo e as cláusulas abusivas", in RDC n. 15, jul/set 1995, p. 5-19 e "Control de la publicidad y comercialización"RDC n. 12, out/dez 1994, p. 12-16; Roberto M. López Cabana "Ecología y consumo" RDC n. 12, p. 25-28 e, após, 1994: Gabriel A. Stiglitz - Danõ moral individual y colectivo, medioambiente consumidor y dañosidad coletiva, RDC n.19- jul./set. 1996, p. 68/76, Atilio Aníbal Alterini - Bases para armar la teoría general del contrato em el derecho moderno,RDC n.19- jul./set. 1996, p. 7/24; Rubén S. Stiglitz - Seguro contra la responsabilidad civil. Control estatal de las condiciones generales de la poliza- estado actual en los paises del mercosul, RDC n.20- out./dez. y cont dectual y contractual de información. El deber de conseso, RDC n.22- abr/Jun. 1997, p. 9/25; Carlos Alberto Ghersi- Los profesionales y la posmodernidad- los abogados, RDC n.23/24- jun./dez. 1997, p. 9/18. os trabalhos de nossos correspondentes. ${ }^{99}$ A pesquisadora líder é correspondente in ternacional da Revista argentina, "Revista de Responsabilidad civil y seguros", cujo Diretor é o Prof. Atílio Alterni, publicado por La Ley, Buenos Aires e da revista belgo/inglesa Consumer Law Jornal, que tem como editores gerais Thierry Bourgoignie (Univ. de Louvainla-Neuve) e Geraint Howells (Univ. of Sheffield), publicada pelo Centre de Droit de la Consommation-CDC..$^{100}$

Outro exemplo de colaboração com o Brasilcon foi a elaboração e a publicação do relatório de pesquisa exaustiva sobre segurosaúde realizado pelo grupo no TJ/RS da entrada em vigor do CDC até a elaboração da lei de seguro-saúde, de 1996 a 1998. Este relatório foi publicado na Revista do Instituto (Revista Direito do Consumidor/RT ${ }^{101}$ e no livro do Instituto "Saúde e Responsabilidade" em 1998 e fazia parte de uma pesquisa do Brasilcon sobre a jurisprudência brasileira em seguros e planos de saúde, coordenada nacionalmente pelo Prof. Dr. José Reinaldo de Lima Lopes (USP). Tive a oportunidade de coordenar a pesquisa no Rio Grande do Sul e Paraná, realizada no Rio Grande do Sul com a ajuda da Docente convidada alemã, Dra. Harriet Zitscher e contando no Paraná com a contribuição no levantamento dos casos da acadêmica da PUC/PR, Caroline Araújo, também co-autora do relatório do Grupo.

O Grupo fornece jurisprudência atualizada para a Revista do Instituto, Revista Direito do Consumidor, que atualmente coordeno, revista especializada considerada a $3^{a}$ Revistä mais vendida pela Editora $\mathrm{Re}$ vista dos Tribunais e editada em São Paulo. Da mesma forma, a professora alemã Dra. Harriet Zitscher publicou pelo Brasilcon, com apresentação minha, seu livro "Metodologia do ensino com casos práticos- Exemplos do Direito do Consumidor" 102 , inaugurando uma nova linha de publicações do Brasilcon/MG.

${ }^{99}$ Assim foram publicados, na Revista Direito do Consumidor, os trabalhos de nossos correspondentes da Argentina: Gabriel Stiglitz- Modificaciones a la ley argentina de defesa del consumidor y su influencia en e mercosur, RDC n.29- jan./mar. 1999, p. 9/20; Carlos Alberto Ghersi- La caracterización de los servicio professionales de a a acia. El poder cultural y la desigualdad en la formación contractual. RDC n.25-jan./ma 1998 p. 9/18 e Consumo sustentable y medio ambiente, RDC n.31- jul./set. 1999, p. 97/103; Medida anticipativa 1998, p . Prevencion de agromiti- Redes Contractuales: sistemica del contrato, Revista n 33- jan/mar. 2000, p. 51/77; Ricter RC n.28- out./dez 1998, p. 22/58, Esquema de una Alterini- Tendencias en la contratación moderna, RDC n.31- jul./set. 1999, p. 104/114 e Roberto M. Lopez Cabaña- Defesa jurídica de los más débiles, RDC n.28- out./dez. 1998, p. 7/21.

100 Veja Informações sobre jurisprudência e legislação brasileira, artigos de Claudia Lima Marques, no "Consumer Law Jol" (CDC Puricar leasing Law Jorna" (CDC Publications, Belgica), vol. 7 (1999), p. contracts- Repayment indexed in dollars -Currency devaluation - Court apples proper code" "Brazil - New healph insurance law", no vol.8 (2000), com Gabriel Stiglitz: "New Consumer Protection Laws in Mercosur" e a aparecer: "The cigarette industry have the burden of proving that nicotine is not addictive to consumers".

${ }^{101}$ Relatório de Pesquisa quantitativa e qualitativa de jurisprudência gaúcha sobre seguro-saúde e o CDC, realizada " Claudia Lima Marques e Harriet C. pelo Gro dis Zitscher, conjuntamente com estudantes, publicado na Revista Direito do Consumidor (São Paulo), vol. 29,
mar 1999, p. 88 a 105:"Relatório BRASILCON sobre seguro-saúde no TJRS, de 1991 até maio de 1998"

mar 1999, p. 88 a 105:"Relatório BRASILCON sobre seguro-saúde no TJRS, de 1991 ate maio de 1998 "
${ }^{102}$ Livro de Bolso, "Metodologia do ensino com casos práticos- Exemplos do Direito do Consumidor" Ed. Del Rey, Belo Horizonte, 1999. Apresentação de Cláudia Lima Marques, p. 1 a 19.

Revista da Faculdade de Direito da UFRGS, v. 20, Outubro/2001 
Em matéria de relações interdisciplinares e interinstitucionais, mister destacar que o grupo possui uma interface muito importante com o Juizado de Pequenas Causas da Faculdad de Direito da UFRGS, uma vez que geralmente mestrando em estágio docente do Grupo coordena tal posto do Juizado ou lá realiza suas pesquisas de Mestrado em Direito do Consumidor com a FEE-Fundação de Economia e Estatística do Estado do Rio Grande do Sul, uma vez que contamos com um economista da FEE acompanhando e orientado os trabalhos sobre regulação, agências reguladoras e outros trabalhos voltados para o estudo do impacto da desestatizações frente as consumidores e com a AGERGS, uma vez que vários egressados do grupo trabalham e assessoram a Agência Reguladora do Estado do Rio Grande do Sul.

Na UFRGS, o grupo mantém contatos com o CEDEP, Centro e Biblioteca especializa da em Integração e seu curso de Especialização Interdisciplinar "Mercosul e Integração" (IFCH/
UFRGS), coordenados pela Profa. Dra. Maria Suzana Arrosa Soares, uma vez que os alunos de iniciação científica lá realizam suas pesquisas e todos os professores envolvidos no grupo, ministram aulas neste curso, ${ }^{103}$ assim como com o Curso de Especialização da Faculdade de Direito da UFRGS “O Novo Direito Internacional". ${ }^{104} \mathrm{O}$ grupo também coopera com o projeto TERMISUL, na elaboração de um dicionário de termos do Direito Ambiental Internacional, coordenado pela Profa. Dra. Maria da Graça Krieger. ${ }^{105}$

Em matéria de relações internacionais, ${ }_{1} 106$ o grupo mantém contato com a Universidade de Buenos Aires, com a cátedra da Carlos Alberto Ghersi (Direito Civil: Obrigações e Contratos), sendo que vários alunos do grupo puderam participar de Congressos na Argentina em 1993, 1994, 1997 e 1998, os professores do grupo são convidados anualmente a palestrar na Argentina e os professores da cátedra no Brasil. Da colaboração destes dois grupo nas-

${ }^{103}$ São professores do Curso, além da autora, as professoras Vera Fradera, Martha Olivar e Fabiana Ramos, além do professor convidado DAAD/CAPES, Ulrich Wehner.

${ }^{104}$ São professores do Curso do Departamento, além da autora, que o coordena junto com o Prof. Manoel André da Rocha, as professoras Vera Fradera, Martha Olivar e Fabiana Ramos, além do professor convidado DAAD CAPES, Ulrich Wehner.

${ }^{105}$ Cooperaram com o Projeto os alunos Fábio Morosini e Fernanda Barbosa, além da líder do grupo.

${ }^{106}$ Como conclama FERNADEZ ARROYO, Diego, Propuestas para la enseñanza y la investigación del Derecho Internacional Privado en América Latina, no livro "Jornadas de Derecho Internacional', Ed. OEA/Sec. de Asuntos Jurídicos, 2000, p. 93 a 112, há que se criar um "jurista americano abierto al mundo",p. 96 e especialmente frisar os estudos e pesquisas na "integración latinoamericana", p. 97.

Revista da Faculdade de Direito da UFRGS, v. 20, Outubro/200

ceram várias publicações conjuntas, na Argentina ${ }^{107}$ e no Brasil. ${ }^{108}$ Assim também mantêm o grupo colaboração com a cátedra do Prof. Ricardo Lorenzetti, da UBA e Prof. Gabriel Stiglitz, univ. de La Plata, com a Univ. de Rosário e Univ. Nacional del Litoral, Santa Fé.

\section{Conclusão}

Como se observa, é possível realizar pesquisa em grupo, frutífera e séria, em Direito. O método aqui retratado é apenas um, muitos outros podem ser desenvolvidos e aperfeiçoados pelos colegas interessados em pesquisa.
A pesquisa em Direito internacional é um caminho aberto para o trabalho conjunto de criação e evolução do pensamento e da doutrina Latino-americana. A colaboração com a sociedade civil organizada não possui apenas o caminho da extensão, também pode ocorrer através da pesquisa acadêmica e publicações direcionadas para a solução dos problemas regionais ou setoriais. A Universidade Brasileira evoluiu muito no que concerne a pesquisa de iniciação científica e este tem se mostrando um caminho positivo para alunos e professores-pesquisadores também no Direito. Esperamos que este testemunho possa motivar e ajudar.

${ }^{107}$ Em 1993 veja capítulo de Livro publicado na Argentina, "MERCOSUL - Perspectivas desde el Derecho Privado", Carlos Alberto Ghersi(Director), Editorial Universidad, Buenos Aires, 1993, p. 167 a 209: Cap.VIII"Tranferencia de Tecnología" e 1996 - Parte Brasileira do Capítulo IX do Livro coletivo publicado na Argentina, MERCOSUR - Perspectivas desde el derecho privado - Segunda Parte", org Ghersi, Carlos Alberto, Editorial Universidad, Buenos Aires, 196, tradç̧ão para o espanhol de Carlos Alberto Chersi, pg. 199 a 226. Cap.IX-"Los derechos del consumidor. Una visión comparativa entre el Brasil y la Argentina. A) El Código Brasileño de Defensa del Consumidor y el Mercosur" e em 2000 , capítulo de Livro publicado na Argentina, "Los Nuevos Daños- Soluciones modernas de reparación", vol. 2, Carlos Alberto Ghersi (Director), Editorial Hammurabi, Buenos Aires, 2000, traduzido para o espanhol, pg. 69 a 105: Cap.IV-"Contratos de Time-Sharing en Brasil y la protección de los consumidores: critica al Derecho Civil en tiempos posmodernos".

${ }^{108}$ Assim foram publicado os artigos dos Assistentes da Cátedra de Carlos Alberto Ghersi, Manuel Cunha Rodriguez (El Sistema de Franchising y la tutela de los consumidores y usuários en el derecho argentino, in Revista da Faculdade de Direito da UFRGS, vo. 13, 1997, p. 147-172), Graciela Lovece (El tiempo compartido, , in Revista da Faculdade de Direito da UFRGS, vo. 13, 1997, p. 131-146), Eduardo Barbier (La tutela del cliente bancario desde la ley de defensa del consumidor en el derecho argentino, , in Revista da Faculdade de Direito da UFRGS, vo. 13, 1997, p. 99-116), Célia Weingarten (Estado de la doctrina y jurisprudencia en la responsabilidade medica, in Revista da Faculdade de Direito da UFRGS, vo. 13, 1997, p. 39-50). 